MARC THOMAS \& JEAN-PAUL VAN BELLE

\title{
VIRTUALIZATION FOOTPRINT: WHY RE-INVEST? ${ }^{1}$
}

\author{
How could re-investing with newer technology help to better utilize existing and new servers and \\ products?
}

Mark Dumas, a Systems Specialist at a Telecommunications Company located in South Africa needed to make decisions regarding the current virtualized infrastructure platform. These decisions also involved the renewal of hardware that had reached the end of its maintenance period and the latest virtualization platform software. Dumas further needed to formulate a plan to ensure that there was enough capacity for systems to meet current and future growth. As part of this process, Dumas had started analyzing the costs of infrastructure and virtualization products, and the newer features available with the newest technologies which could be beneficial to business.

At the time of the case, South Africa had four major cellular companies that offered mobile voice, messaging and data to millions of South Africans: Vodacom SA, MTN, Cell C and Telkom Mobile (see Exhibit 1).

A particular challenge that Dumas faced was an existing collection of physical servers that hosted numerous virtual machines. The maintenance contract on these machines had reached the end of their lifespan, because the hardware was more than 5 years old. These many virtual machines needed to be hosted elsewhere, presumably through the purchase of new servers; otherwise the maintenance contracts on the legacy hardware would need to be extended and compute resources needed to be upgraded to align with the existing servers. Another challenge was analyzing whether the current virtualization products remained the best fit for the company's needs, or whether other virtualization products could potentially be more cost effective and could deliver the same, or improved, functionality.

In considering how to address these decisions, Dumas had conducted research on a variety of virtualization products, comparing them to the current virtualization solution. He had conducted similar research on server environment options, including the purchase of new servers, migrating virtual machines within the existing server environment, and moving towards cloud technologies. Now he needed to prepare his recommendations. Abbreviations and technological jargon have been categorized in a table (see Exhibit 2).

\footnotetext{
${ }^{1}$ Copyright (C) 2017, Muma Case Review. This case was prepared for the purpose of class discussion, and not to illustrate the effective or ineffective handling of an administrative situation. Names and some information have been disguised. This case is published under a Creative Commons BY-NC license. Permission is granted to copy and distribute this case for non-commercial purposes, in both printed and electronic formats.
} 


\section{Virtualization and Cloud Technologies}

Two technologies were particularly relevant to Dumas' decision: virtualization and the cloud computing platform.

\section{Cloud Computing}

Cloud computing provided access to a portal through which compute resources (Memory, CPU and storage) could be acquired on demand over the internet without having to procure expensive server hardware. This allowed companies to use those resources as a pay as you use service. Cloud platforms were built on virtualization technologies which spread over datacenters locally and worldwide. Global companies offering those services included Amazon, Microsoft, VMware and Google. The use of cloud computing offered cost savings, efficiency within an IT environment and could reduce the cost of management of data and security. The cloud had opened doors for small-to-medium enterprises (SME) by providing access to advanced IT technology previously available only to large enterprises. This provided platforms for competitive growth, entrepreneurship and innovation. Cloud architectures had also become attractive to Africa when finance was limited, or capital expenditure needed to be reduced (See Exhibit 3).

There were 3 types of cloud platforms:

1. Public Cloud: Resources were made available to the public as a free service or as a pay per usage model.

2. Private Cloud: Resources were similar to the public cloud, but only available to dedicated organizations.

3. Hybrid Cloud: Was used as a mixture of public and private.

Cloud computing in Africa was still in the process of early growth, with South Africa having a higher activity in usage of Cloud activity. There were companies present in South Africa that offered those solutions, like Amazon and Internet Solutions as well as telecommunication companies (Gillwald, Moyo, \& Stork, 2012).

\section{Virtualization}

Virtualization was a server technology that allowed multiple simulated (virtual) machine instances to run on a single hardware platform. It offered the ability to provide shared resources in the infrastructure environment. Virtualization was implemented by taking a physical server, loading a virtualization operating system (Hypervisor) and hosting multiple virtual machines. Each virtual machine operated as if it were a separate computer. The benefit of the approach was that compute resources could be used more efficiently, rather than having only one operating system or application running on a single physical server. With virtualization you could have multiple operating systems, databases or applications running, which were balanced across the available compute resources (see Exhibit 4).

Virtualization had become a good investment, because the features it provided were beneficial and helped increase scalability, flexibility and agility in IT, while saving on capital and operational expenditure. Virtualization had also transformed datacenters into a more software defined environment, in which operations had become more automated, greener and easier to manage (see Exhibit 5).

With virtualization, physical servers could also be configured into a cluster (more than one physical server where virtual machines could be hosted) which allowed scalability and redundancy when a physical box would fail (see Exhibit 6). When upgrading virtual machines, it could take less than 3 
minutes for the system to reconfigure itself. Virtualization of physical server hardware was also the backend for Cloud technology, providing resources for people to request servers, applications and databases without the need to purchase hardware.

Virtualization also ensured that administration became more centralized and simplified. Provisioning times of servers were decreased as compared to physical provisioning. The possibility of improved disaster recovery was improved and simplified.

The evolution of virtualization had opened opportunities for many companies in utilizing their hardware more efficiently and saving costs within datacenter environments. Broadly speaking, the benefits of virtualization were characterized as follows:

- Cost: This was among the most widely cited benefit of virtualization. Cost reduction was due to consolidation of hardware and reduced purchasing of hardware (Kedia, Nagpa, \& Singh, 2013, p. 36). This type of consolidation also allowed smaller physical servers to become more powerful virtual servers. This allowed cost reduction on hardware, operation costs, personal floor space, and power consumption as well as licensing (Sahoo, Mohapatra, \& Lath, 2010, p. 224). Virtualization might not save a huge amount of money in the beginning, but over time it would be able to reduce costs on hardware and electricity, which becomes a huge benefit for SMEs (Erbs, n.d.).

- Hardware Utilization: This was another benefit of the use of systems virtualization, as hardware was more efficiently utilized by running multiple operating systems on the same physical hardware (Kedia, Nagpa, \& Singh, 2013, p. 36). The virtual machines utilized the idle resources that were available on a physical server and would use the storage capacity more efficiently (Sahoo, Mohapatra, \& Lath, 2010, p. 224). This reduced the amount of hardware and storage purchased to host company operations and data (Erbs, n.d.).

- Downtime: This was a serious threat to the operations of a company. With systems virtualization, there were improvements due to faster recovery (Kedia, Nagpa, \& Singh, 2013, p. 36). Availability was improved with virtual machines that could migrate from one host to another, while maintenance or hardware replacements needed to be performed. Once those operations were completed, the virtual machines could be migrated back to the host they originally resided on. The benefit of this was that virtual machines could be migrated online, without any disruption to services (Sahoo, Mohapatra, \& Lath, 2010, p. 224).

- Business Continuity: This referred to the ability of a business to continue functioning in the presence of adverse factors. Related to downtime, systems virtualization enabled rapid recovery from any outages or hardware failures. This reduced the loss of revenue that a business could suffer due to extended outages. Reduced downtime, however, depended upon the correct procedures being in place. Where virtual machine migrations were implemented, faster recovery from hardware problems could be ensured (Erbs, n.d.).

- Scalability: Scalability of computing could be achieved since virtual machines could have hardware upgrades performed online, and physical servers could be removed from the cluster while virtual machines were migrated to other physical servers. When performance capacity from a hypervisor became heavily utilized, virtual machines could be automatically migrated to other hypervisors (which belonged to the same cluster) to address the performance needs that virtual 
machines demanded. The cluster itself could also be expanded by adding more hypervisors when needed (Sahoo, Mohapatra, \& Lath, 2010, p. 224).

- Backups and Disaster Recovery: This became much simpler and faster with systems virtualization (Kedia, Nagpa, \& Singh, 2013, p. 36). Businesses could crumble under the pressure of disasters like fire, theft as well as other natural disasters. Concern over this was less with virtualization if backups were done regularly (Erbs, n.d.). A VADP backup was a technology that worked well with virtualization, and allowed the backup media to speak to the API of the virtualized product, without the need of having agents installed inside the virtual machines. VADP created a snapshot of a virtual machine and backups would occur from that snapshot. Once backups were completed, it would revert back to the original snapshot, and delete it once all was successful. This method was beneficial for replication between sites for disaster recovery purposes as well as off-site backups (Mohan, Alam, Fowler, Gopalakrishnan, \& Printezis, 2014).

- Flexibility: This was an important benefit of virtualization. Migration of virtual machines between hosts could be achieved and done without effort or any downtime. Hardware resources such as CPU, memory and disk space could also be added while a virtual machine was online (Sahoo, Mohapatra, \& Lath, 2010, p. 225).

Dumas knew that the above-mentioned options (Virtualization and Cloud technologies) contained many factors beneficial to his environment, but remained aware that he needed to spend time researching the various products and solutions that were available. Although there were calculators that worked out the total cost of ownership available from the vendor's website, it seemed that each vendor's price comparison worked out to be cheaper than the other. Dumas concluded that he had to ask consultants to come on-site to analyze and understand the environment. Once the analysis was completed, a true reflection of the costs could be worked out. With the Cloud solution, a comparison needed to be made between the costs of hosting in-house versus hosting in the Cloud, as well as the benefits of both.

\section{South African Telecommunications Industry}

Telecommunication companies in South Africa provided efficient and effective services to urban areas that included voice and data functionalities. Telecommunications has become one of the fastest growing areas within the economy. Telkom dominated the fixed line service in South Africa and was listed on the Johannesburg Stock Exchange (JSE). The majority of the company was owned by the South African Department of Communications. In 2006 Telkom's monopoly in fixed lines was challenged by Neotel, owned by Tata Communications, which became the second service provider for voice and data in South Africa (see Exhibit 7).

The explosive growth of mobile data and voice usage in South Africa was fueled by rapid expansion in mobile phone ownership. Four mobile service providers competed locally as well as in other parts of Africa. The companies were MTN, Vodacom (majority owned by Vodafone), Cell C and Telkom mobile (part of Telkom). Fiber connectivity has also expanded and the race between service providers has begun.

Over the past two decades, telecommunications infrastructure has improved steadily compared to other types of infrastructure in South Africa. This rapid growth was largely due to both the innovations of mobile technology and the telecommunications markets being relaxed by government. The investments that were spent in telecommunications increased growth in the industry, which created economic growth and improvement of productivity and efficiency within mobile, fixed lines and the Internet (Chavula, 2013). In Africa the mobile market has continued to grow rapidly with the number of mobile subscribers having increased by $13 \%$ over the past 5 years. This was despite that fact that there were still many people that remain unconnected. About 50\% of the population in Africa (a total of 550 million people) did not 
subscribe for the services of mobile connectivity. While the availability of fixed lines was low in Africa, many people on the continent owned mobile phones, making mobile the most efficient way most people would be able to access voice and data services. The numbers of mobile subscribers showed that $50 \%$ of mobile users were also internet users. This was an increase from $26 \%$ recorded in 2010 . The numbers were expected to increase to $75 \%$ by 2020 . McKinsey predicted that by 2025 , the internet could account for nearly $\$ 300$ billion of Africa's GDP, which would be caused by its impact on various sectors like retail, healthcare, education and agriculture.

\section{The Telecommunications Company}

The Telecommunications Company Dumas worked for was one of the leading mobile operators in South Africa. It provided mobile, messaging and data services to millions of people across the country. It also offered managed services in 40 countries across the continent. The company's vision was to ensure that customers always got the best experience. This means making businesses and processes run more efficiently by building diverse and talented teams, and by transforming society and stakeholder trust.

Customers had the option to choose between prepaid or contract products. Prepaid solutions allowed customer control over how much was available for them to spend without being locked in to long-term contracts. Contract solutions made it convenient to pay for services that were debited monthly. Those services also allowed customers to enjoy handsets that kept them connected wherever they find themselves in the world.

From the enterprise side, the company offered internet and virtual private networks that were available via wireless, fixed-line, satellite or converged technologies. Hosted cloud services were also offered, allowing companies to utilize emerging available technologies.

\section{The IT Department}

Dumas belonged to an IT department that believed in providing efficient and effective IT solutions to the internal customers. Their core focus was to help in providing efficient, secure, stable and effective platforms for hosting applications. Virtualization and automation had become part of the core platform that provided resources for production, development and test environments across various operating systems, applications and databases. One of the key accountabilities was to perform and to plan capacity for systems in order to meet current and future operational requirements. Research on newer technologies was also done to bring value into business and to keep up to date with various technologies.

The Telecommunication Company that Dumas proudly worked for, was obsessed with providing various services efficiently and effectively to their internal and external customers. Business and IT alignment had become one of the greatest priorities, which encouraged mature attitudes and working together to reach a common goal.

Aligning business and IT strategies created a positive impact on IT investments and enhanced working relationships between business and IT, which increased an organization's competitive advantage, future growth and profit (Yayla \& Hu, 2009).

Dumas' focus was to analyze the environment by researching technologies and finding ways that could potentially save on operational and capital expenditure. The goal was also to become more competitive with infrastructure, and to boost resilience and capacity across the infrastructure environment. 


\section{IT Architecture}

The 3 key infrastructure areas that Dumas needed to focus on were the company's:

- Virtualization Environment

- Server Hardware Environment

- Cloud Technologies

\section{Virtualization Environment}

Virtualization was one of the solutions that offered many benefits to the Telecommunication Company which Dumas worked for. Reduction of capital expenditure was improved by replacing many legacy physical servers by virtualizing them into virtual machines. This reduced purchasing of physical servers to replace the legacy physical servers. With virtualization, running numerous operating systems, applications and databases became a reality. This proved to use physical compute resources more effectively by providing cost savings and preventing wastage of compute resources. The virtualization environment in Dumas's company hosted over 3600 virtual machines and also provided functions like high availability, resource balancing between virtual machines across physical servers, limited downtime when hardware failed and disaster recovery. The product used for virtualization was the VMware suite with server automation. Virtual machines that were hosted on the virtual platform consisted of small, medium and large compute sizes which hosted high end applications.

\section{Virtualization Possible Options}

As a result of rapid advances in virtualization over the past decade, many alternatives to the company's existing technologies were possible (see Exhibit 8). Among those that Dumas was considering were the following choices from a variety of vendors. The reason for considering these options was to compare what was needed and what would suit the organization (see Exhibit 9).

- VMware Vsphere 6 Suite: VMware was the virtualization leader in many datacenters and was the dominant virtualization platform on the market. VMware Vsphere 6 had increased their scalability by supporting up to 128 virtual CPU's and 4TB virtual machines. This allowed for large virtual machine deployments for big data (Hadoop). VMware also increased their physical host servers' Hypervisors to be able to host 1024 virtual machines, by allowing physical servers to support up to 480 CPU and 12TB memory. VMware created a clustered environment that was able to host up to 64 servers. The other feature that improved was the graphics card feature from NVIDIA, which improved virtualized solutions that required strong graphic features. VMware vMotion improved virtualized solutions by being able to migrate machines between sites without any downtime. VMware storage features allowed improvements on the virtual SAN (Storage Area Networks) and offered virtual volumes which allowed virtual machines to create directly onto the storage, without having dependencies on the Hypervisor. This took away the dependence from hypervisor layer, which allowed better performance, instant block reclaiming and storage control. Networking also improved with virtual networks (NSX). VMware was generally considered to be more expensive than other hypervisors, although different licenses were available that could suit datacenter needs. VMware also provided high availability that reduced downtime of virtual machines when server hardware would fail.

- Microsoft Hyper-V 2016: Microsoft virtualization products had dramatically improved with Hyper-V 2016. Hyper-V concentrated on improving backups and checkpoint solutions. With backups, any third party vendor could integrate with Hyper-V. With checkpoints, the virtual 
machines would assume that data had been recovered from backup, and reboot, which would protect the integrity of the replicated data rather than restoring it to its running state. Hyper-V also concentrated on cluster upgrades and virtual machine migrations when servers had to be upgraded to later Microsoft hypervisor versions. Hyper-V concentrated on their virtual machine compute resilience with high availability when physical servers failed. When physical servers failed due to hardware or operating system crashes, virtual machines would be able to restart on other physical servers within the cluster, causing minimal downtime. Another feature that had become a big venture were containers. Hyper-V made this possible by creating servers as NANO servers or Server Core versions. Containers used less resources, were light-weight and faster than normal virtual machines. Hyper-V server licenses also came at a cost and supported up to $320 \mathrm{CPU}$ and 4TB memory, with supporting 1024 virtual machines that could run per physical server.

- Citrix Xen Server: The big attraction regarding Xenserver was that it had been developed from an open source environment and had also been developed for enterprises workloads. Xenserver Hypervisor costs were free, although the real costs came in when Citrix support needed to be included. Xenserver also offered some of the same features as VMware and Microsoft with failover, high availability and shared resources. Amazon Webservices used Xenserver as their EC2 platform for cloud as well as a few other cloud service providers. Although not as powerful as VMware or Hyper-V, it all came down to what requirements were needed in the organization and what would be needed in the future.

- Containers: This was the new IT trend that had appeared on the market, although it had been available for a while. The difference between a container and a virtual machine was that a container was more light-weight, used much less compute resources than a virtual machine, and it was open to run on Linux distribution, Microsoft and on top of any infrastructure. Containers could securely isolate applications from other application containers. Docker had been one of the products that invested in container technology, while Microsoft had also entered with Nano server for container functionality. Containers ran on Linux technology and consisted of an entire runtime environment, applications, dependencies, libaries and other binaries and configuration files that were bundled into one package. The difference between containers and virtual machines was that with virtual machines, the package itself was passed via the virtual machine that consisted of an operating system and could be huge in size. Multiple containers could share an operating system which was in read only, and the application package had its own mount to make changes to it. In practice, a single server could host many more containers than virtual machines, as containers could be a few megabytes and virtual machines could be a few gigabytes. Containers could be executed on any technology like a laptop, server or in the cloud (see Exhibit 10).

There were many other virtualization products choices on the market that could be looked at, and could be configured to suit what would be needed in your environment within functionality costs and efficiencies.

\section{Server Hardware Environment}

The existing infrastructure consisted of a mixture of individual x86 servers and converged server systems, which were used for the virtualized platform. The purpose of those servers was to offer on-demand deployments for applications, operating systems and databases. The environment consisted of 169 physical servers that hosted over 3600 virtual machines. There were individual servers that were 
connected to Storage Area Networks (SAN) and converge systems that were connected to their own shared SAN within its own enclosure. In the environment there were 22 servers that were over the 5 year maintenance contract and were not up to specification as the existing environment. There were also numerous amounts of virtual machines hosted on those physical servers. Those servers had reached their threshold limit within compute resources. Deploying/upgrading virtual machines was not possible when the demand for resources was huge. Maintaining those servers meant that there would be an operational cost on maintenance contracts and hardware components had to be purchased to upgrade to the same specifications as the existing server. Dumas had to keep in mind that a time would come when those servers would need to be replaced due to firmware and hardware components becoming obsolete.

\section{Hardware Platform Alternatives}

Similar to the virtualization case, a number of alternatives for upgrading, enhancing or replacing the existing hardware infrastructure were being considered (see Exhibit 11).

Technology was always advancing and becoming better in terms of performance; implementing the latest technology could save a considerable amount of money in the future. Keeping up to date with trends intended for new technology, and evaluating these objectively against the financial impact for a company, helped to align new technology with company strategy and competitiveness. New technology helped to provide more with less money, and replacing older hardware with new hardware reduced additional complexity and costs (Cassidy \& Cassidy, 2009).

\section{x86 Blade Server Hardware}

x86 was a server hardware that consisted of CPU, memory, storage/storage ports and network ports which were all configured into a blade chassis. These types of hardware hosted applications like e-mail servers, webservers like google, databases, virtual machines and operating systems. This was part of the hardware that made up the datacenter. The reason for choosing x86 hardware with virtualization was that it became just as efficient and effective, and offered most of the benefits and features found on expensive mainframes at a lower price and operational expenditure cost. Although mainframes allowed nearly no downtime, due to the firmware configured with virtualization on $\mathrm{x} 86$, there was minimal downtime due to high availability, load balancing and scalability. With blade servers you needed to allocate network ports and local storage for SAN (Storage Area Network). The setup of the server was a manual process.

\section{Converged Infrastructure Hardware with x86}

Converge systems had also become part of the "all in one" solution where the enclosures consisted of blade servers chassis, shared storage devices, and virtual connect network devices which were preconfigured at the factory of the vendor. The vendor asked for certain specifications from the company (IP, hostnames, operating systems and storage capacity sizes). When the converged system arrived on site, it was ready to plug in and powered up without the need to manually configure the system. Those systems came with a network device called virtual connects that consisted of 4 nodes configured with fiber connections, which allocated virtual network cards to be available virtually. The idea was to save costs and physical network port/san port allocations which needed to be allocated to the physical servers. This also improved manageability and easier deployment by saving on time required to configure the system.

\section{Superdome $\times 86$}

HP Superdome was hardware built for mission critical applications which allowed you to virtualize your physical servers into one or more huge virtual servers which could host virtual machines. It consisted of a half rack (4 servers) or full rack (8 servers) configuration that could be purchased, depending on the organizational budget. If one of those blades experienced a hardware fault, the resources that the virtual 
machines were occupying would move over to the other physical servers without the need for virtual machines having to restart or experiencing downtime. This solution offered minimal or no downtime for business. Superdome and virtualization had combined to offer implementation and deployment of virtual machines on a large scale, which also included all sizes for databases and applications. Superdome supported all currently available operating systems and had been tested for performance.

The decision regarding server replacement included considering server retention and upgrading of existing servers. This could save on capital expenditure and operational costs to maintain those servers. The comparisons were made in a table format to decide on the best way forward (see Exhibit 12).

\section{Cloud Options}

Cloud computing was another option investigated by Dumas's company to eliminate the upfront capital investment in hardware, virtualization products and application software. Investigation and research was done to ascertain if moving to cloud computing would be cost effective by moving from a capital expenditure to an operational (i.e., a pay as you use) model for Dumas's company's IT requirements. Cloud computing offered the following services needed within a datacenter:

- Infrastructure as a Service (IaaS) rented hardware resources such as CPU, Memory and Storage where users can deploy software on those virtual servers. The underlying hardware was controlled by the vendor chosen as a cloud solution.

- Software as a Service (SaaS) offered software services which removed the cost of installations, upgrading and maintenance of the software. This software could be accessed via a web browser or a thin client without access to the underlying hardware.

- Platform as a Service (PaaS) offered a platform where users could run and test applications without control of the underlying hardware. Users could have access to the configuration settings of these systems and make changes to these systems.

- Anything as a Service (Xaas) was another component that was offered from the cloud which combined Iaas (infrastructure as a service), PaaS (Platform as a service) and SaaS (Software as a service) in one bundle. This service allowed companies to access numerous services from the cloud and replaced the focus on on-site hosting. Using this service ensured that: no capital expenditure was required, tools and infrastructure were hosted off-site and staff recruitment to manage software and services was reduced. The other important options to consider were the issues of costs over time, having efficient bandwidth/bandwidth speed and lock in contracts.

\section{The Decision}

The decision of re-investing was not primarily motivated by the fact that newer technology was available and that there were hundreds of new features available, which probably would not be used. The main driver was to look at how re-investing with newer technology could help to better utilize existing and new servers and products. New technology also offered newer features that helped organizations to save on everyday costs that could occur in the datacenter by: 
- Conserving capital and operational expenditure

- Reclaiming floor space in a datacenter

- Reducing costs on cooling and energy

- Centralizing and simplifying management and maintenance tasks

- Improving on availability and reliability, which would improve service levels

With new and existing virtual products, server hardware components and cloud technologies, there were options for datacenters to re-examine and realign their strategies. This could help business by becoming more competitive and by reducing costs, with newer features that potentially were virtualized and could offer physical resources by virtually saving on other datacenter component costs. Although saving on costs was a huge factor, careful attention needed to be paid to the products that could replace the existing product, as certain features might not be available and could cost the organization by having to purchase additional products to get to the same outcome.

\section{References}

Cassidy, A., \& Cassidy, D. (2009). A practical guide to reducing IT costs. Fort Lauderdale, FL: J. Ross Publishing.

Chavula, H. K. (2013). Telecommunications development and economic growth in Africa. Information Technology for Development, 19(1), 5-23. http://doi.org/10.1080/02681102.2012.694794

Erb’s Technology Solutions (n.d.) Why virtualization is right for you. White paper. Retrieved from: http://etsconnect.com/resources/white-papers/free-white-paper-virtualization/

Gillwald, A., Moyo, M., \& Stork, C. (2012). Understanding what is happening in ICT in South Africa: A supply-and demand-side analysis of the ICT Sector. Retrieved from: http://www.researchictafrica.net/docs/South_Africa_Country_Report_2013_Final.pdf

Kedia, P., Nagpal, R., \& Singh, T. P. (2013). A survey on virtualization service providers, security issues, tools and future trends. International Journal of Computer Applications, 69(24).

Mohan, S., Alam, F. M., Fowler, J. W., Gopalakrishnan, M. and Printezis, A. (2014), Capacity planning and allocation for web-based applications. Decision Sciences, 45(3), 535-567.

doi:10.1111/deci.12079

Sahoo, J., Mohapatra, S., \& Lath, R. (2010, April). Virtualization: A survey on concepts, taxonomy and associated security issues. In Computer and Network Technology (ICCNT), 2010 Second International Conference, (222-226). IEEE. doi: 10.1109/ICCNT.2010.49

Yayla, A., \& Hu, Q. (2009). Antecedents and drivers of IT-business strategic alignment: Empirical validation of a theoretical model. Retrieved from: https://works.bepress.com/qing hu/46/ 


\section{Biographies}

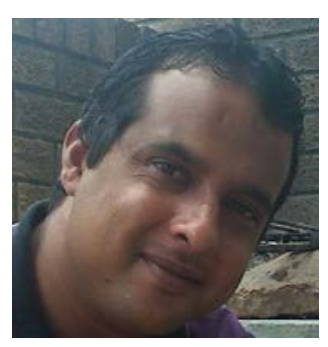

Marc Thomas is a systems support specialist within the Infrastructure environment for one of the biggest telecommunications companies in South Africa. He has completed his Postgraduate in Management of Information Systems at UCT and has over 13 years of IT experience in various areas. He is currently looking after the virtualized environment and focuses on delivering efficient and effective services to all business units.

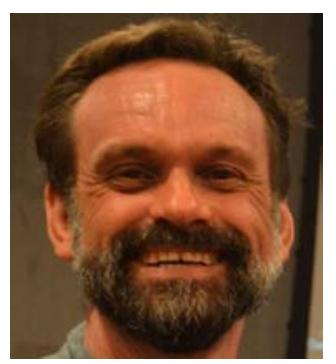

Jean-Paul Van Belle is a professor in the Department of Information Systems at the University of Cape Town and Director of the Centre for IT and National Development. His research areas are the adoption and use of emerging technologies in developing world contexts including mobile, cloud computing, open and big data. His passions are ICT4D - with a focus on emerging technologies as well as data for development (D4D) in an SDG context - and adoption of ICTs by small organizations. He has over 170 peer-reviewed publications including 25 chapters in books and about 40 refereed journal articles. He has been invited to give a number of keynote presentations at international conferences and holds an honorary professorship at Amity University. He currently supervises almost 20 Masters and PhD students and has graduated many more. Jean-Paul has active collaborations with researchers in India, UK, Ethiopia, Kenya and Mauritius. Research interests: ICT for development (ICT4D); emerging technologies; data revolution and SDGs; ICT use by small organisations. 


\section{Exhibit 1: Telecommunications Companies in South Africa}

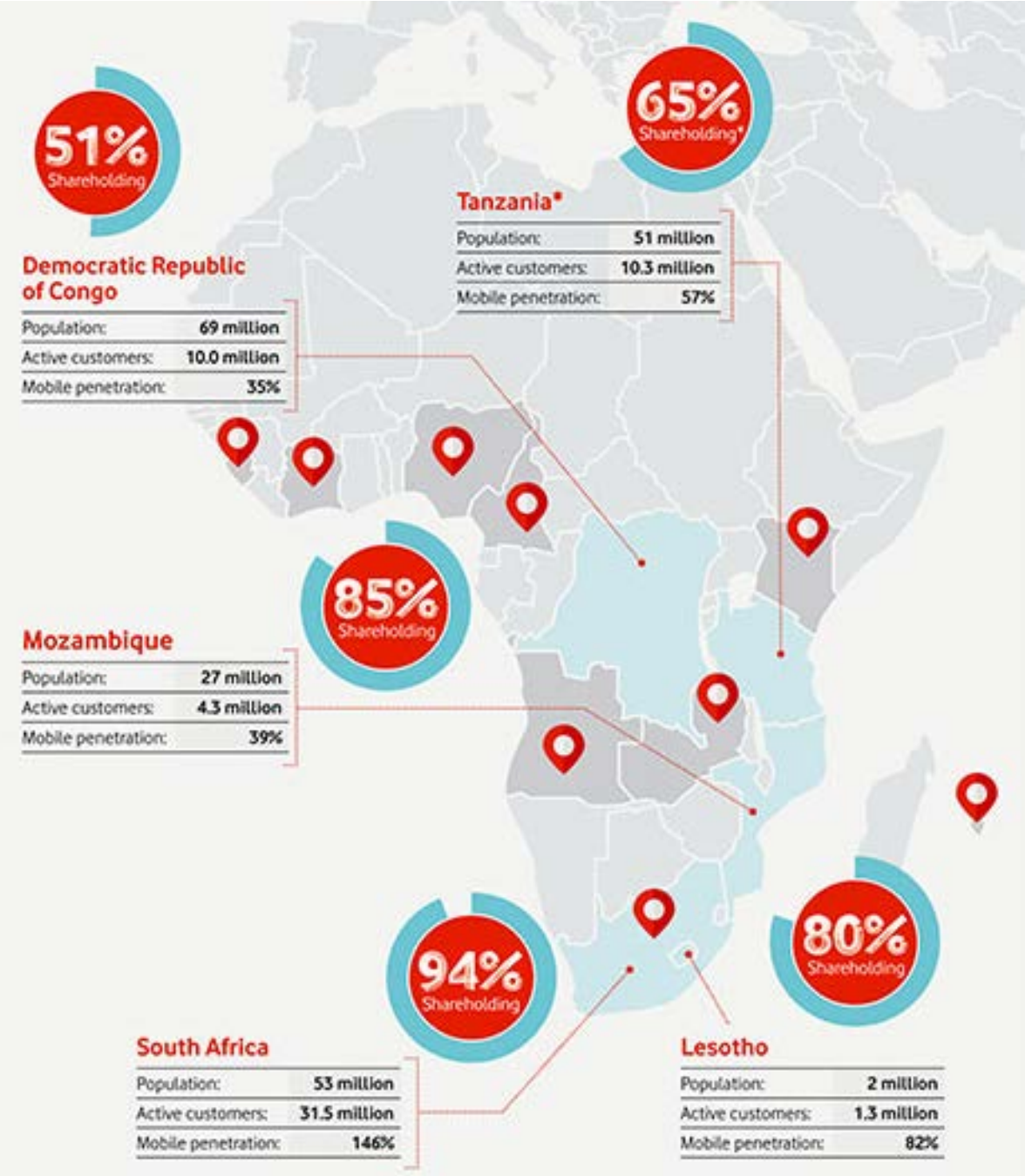

"Vodacom is a leading African mobile communication company providing a wide range of communication services including mobile voice, messaging, data and converged services to over 61 million customers. From our roots in South Africa, we have grown our mobile network business to include operations in Tanzania, DRC, Mozambique and Lesotho. The mobile networks cover a total population of approximately 200 million people. Through Vodacom Business Africa (VBA), we also offer business managed services to enterprises in over 40 countries across the continent. Vodacom is majority owned by Vodafone (65\% holding) one of the world's largest mobile communications companies by revenue."

Source: Vodacom Website (http://www.vodacom.com/about-us/about-us/company-profile) 

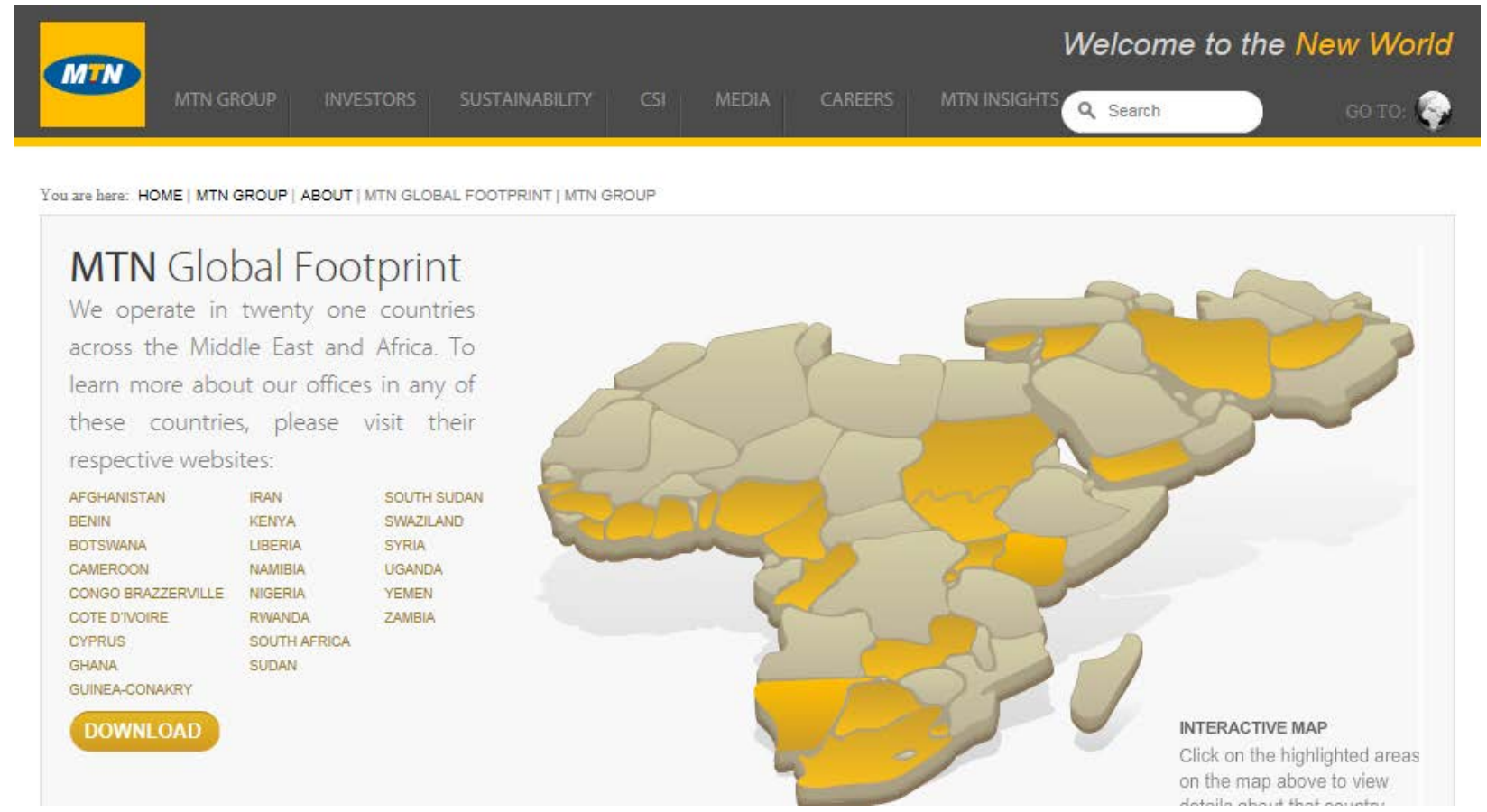

"MTN South Africa forms part of the MTN Group, a multinational telecommunications operator that boasts more than 229.2 million subscribers across its markets in 21 countries in Africa and in the Middle East. In 2011, MTN rolled out the largest network infrastructure development project in the history of the company. This has increased its 2nd generation (2G) network coverage to 98.6 percent of the country's population. In addition, the EDGE and 3rd generation sites of MTN South Africa covers close to 65 percent of the population thereby enabling better call and data connectivity.

MTN has successfully migrated various voice bearer interfaces to internet protocol thereby improving scalability and network simplicity. It has also invested a significant amount of capital in building its own backbone and transmission infrastructure. As a company dedicated on bringing its customers a worldclass internet experience, it has invested substantially in submarine cables to improve broadband capacity. MTN is also the single biggest investor in the West Africa Cable System (WACS), a submarine cable that links South Africa and the west coast of Africa to Europe. However, it has also invested in the Eastern Africa Submarine Cable System (EASSy), a fibre optic cable system that links South Africa and the east coast of Africa to Europe, to further improve network redundancy."

Source: MTN Website (https://www.mtn.co.za/About_us/Pages/MTN_SA.aspx) 


\section{Company Profile}

Telkom is a leading communications services provider in South Africa. We had consolidated operating revenue from continuing operations of R31.7 billion and profit after tax from continuing operations of R2,889 million for the year ended 31 March 2015. Total assets amounted to R42.0 billion and equity attributable to the owners of Telkom to R25.7 billion as of 31 March 2015. The group generated free cash flow of R3.9 billion for the year ended 31 March 2015

As of 31 March 2015, we had approximately 3.4 million telephone access lines in service and 964,196 ports connected via MSAN access. We offer business, residential and payphone customers a wide range of services and products, including:

\footnotetext{
- fixed-line retail voice services using PSTN (Public Switched Telephone Network) lines, including ISDN (Integrated Services Digital Network) lines, and the sale of subscription based value-added voice services and calling plans;

- fixed-line customer premises equipment rental and sales services both voice and data needs and these include PABX, Computers, Routers, Modems, Telephone handsets and other ancillary equipment;

- interconnection services, including terminating and transiting traffic from South African mobile operators, as well as from international operators and transiting traffic from mobile to international destinations;

- fixed-line data services, including domestic and international data transmission services, such as point-to-point leased lines, ADSL (Asymmetrical Digital Subscriber Line) services, packetbased services, managed data networking services and internet access and related information technology services;

- Data Centre Operations includes e-commerce, application service provider, hosting, data storage, e-mail and security services;

- W-CDMA (Wideband Code Division Multiple Access), a 3 G next generation network, including fixed voice services, data services and nomadic voice services;

- mobile communication services, including voice services, data services and handset sales through our mobile brand called Telkom Mobile; and

- other services including directory services, through Trudon (Pty) Ltd, wireless data services, through Swiftnet (Pty) Ltd.
}

Convergence is one of our key strategic initiatives in building a sustainable future for Telkom. We will lead the provision of converged services in South Africa in support of our mission statement: Seamlessly connecting people to a better life.

Source: Telkom Website (http://www.telkom.co.za/about_us/companyprofile/company-profile.shtml)

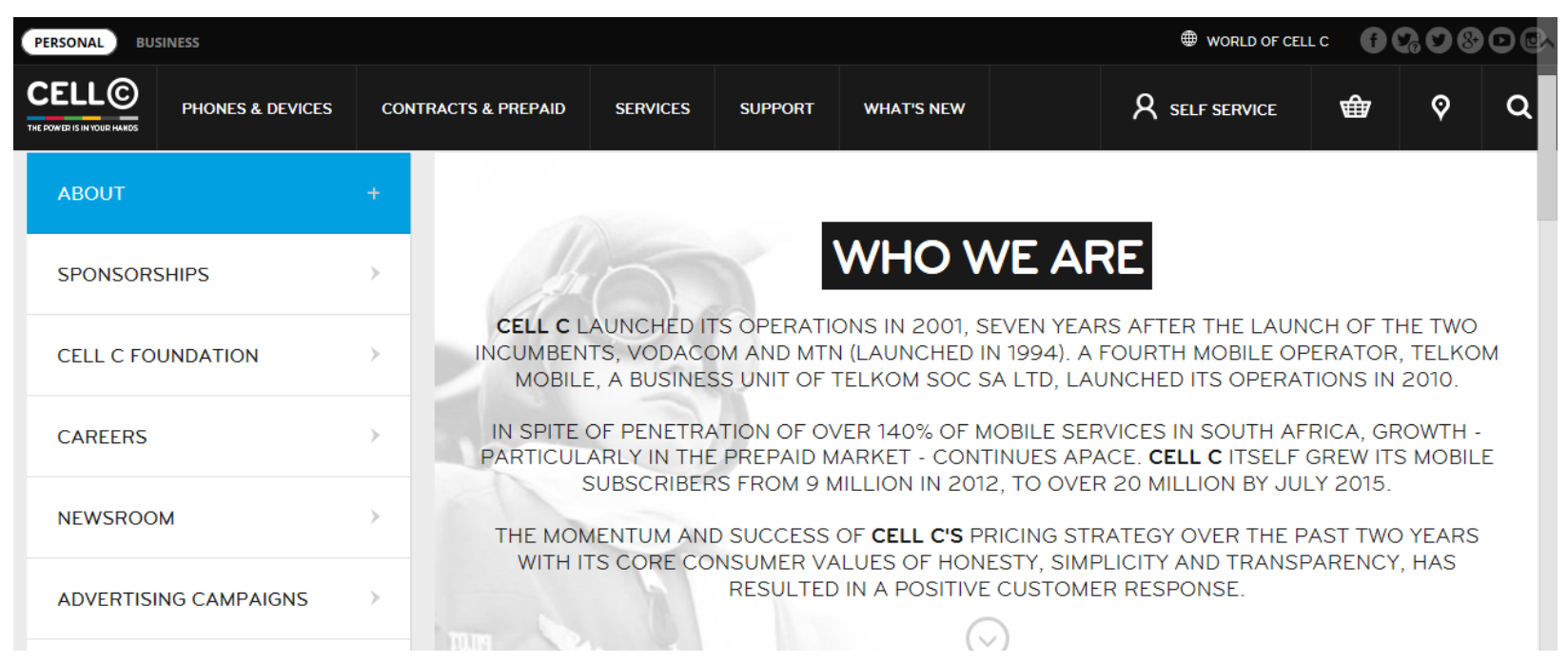

Source: Cell C Website (https://www.cellc.co.za/cellc/about-who-we-are ) 
SA mobile ARPU 2002 - 2015

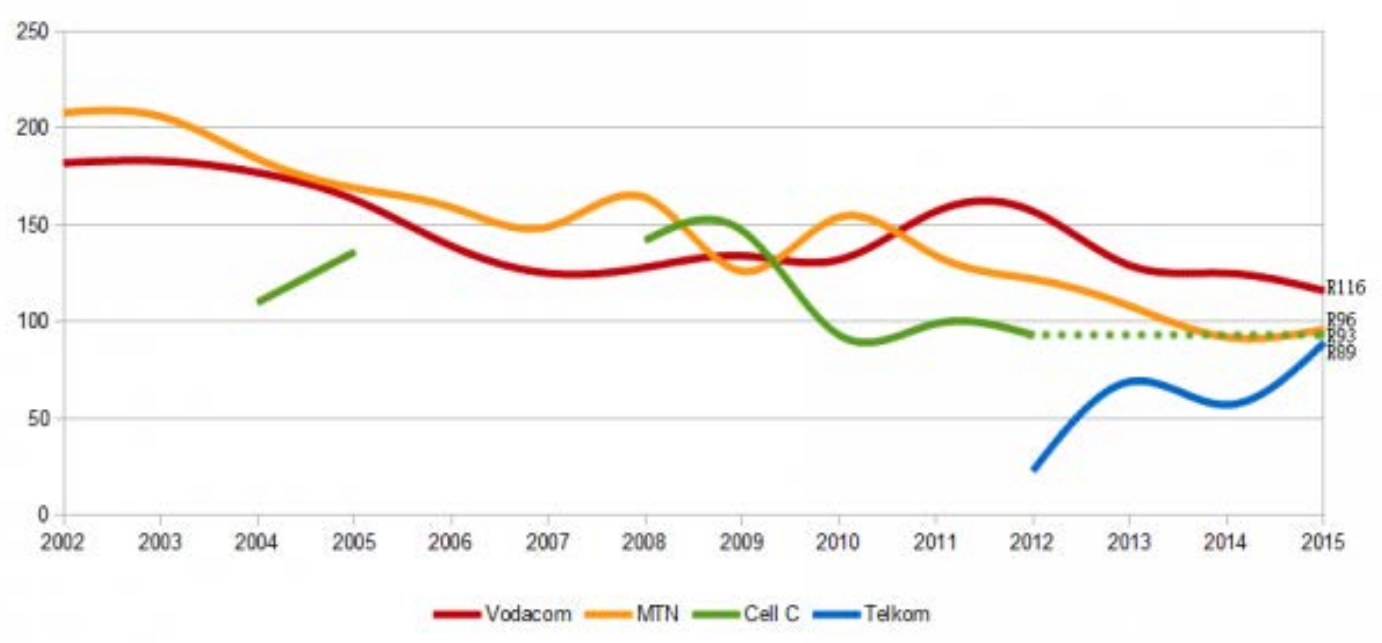

Source: Businesstech Website (http://businesstech.co.za/news/mobile/113398/how-much-moneyvodacom-mtn-and-telkom-makes-from-you/) 


\section{Exhibit 2: Technology Abbreviations Before the Big Read}

- Compute Resources: Compute resources are objects of memory, CPU and storage from a physical server or virtual server.

- Datacenter: Organizations can consist of an area that is dedicated to server infrastructure (consists of servers, switches, cables, air conditioners, Storage Array devices etc.) which is security controlled.

- Virtualization: Refers to creating a virtual instead of physical instance of something. In this case it would be virtual servers, virtual storage, virtual memory, virtual CPU and virtual networking.

- Clustering: Clustering or a cluster is a method of taking physical servers and implementing them into a cluster (having more than one physical server in a cluster).

- Legacy servers: Legacy servers are servers that are too old to meet the demand from an organization and have reached the end of their lifespan.

- Virtual Machine Migration (Migrate/ vMotion): Virtual machines can move between any physical servers within a cluster. This helps especially when there are constraints on compute resources on a physical server, where the other physical servers are available when virtual machines need to migrate, to lower the strain on the busy physical server.

- Hypervisors: A hypervisor is part of the virtualization products that abstracts the physical hardware and presents it to the virtual machines (VMware, Hyper-V, Xenserver).

- Operating Systems: Operating systems are server based low level software that supports a computer's basic functions, and are installed on a physical or virtual machine (Windows, Linux, SUSE).

- High Availability: Reduces the need to purchase standby hardware in case of a failure. Virtualization allows that if a physical server fails, the virtual machines that reside on that server will restart themselves onto other physical servers available in the cluster.

- SAN: Storage Array Network. These arrays consist of numerous amounts of disks in their own enclosure and can be presented to multiple servers over the network. The server will see it as if it is its own hard drive.

- Automation: Automation is a piece of software that takes away the manual work needed in creating and setting up of servers, storage, networking etc. in a virtual environment. This can help reduce hours or days of work into an hour or minutes.

- Snapshot: This allows you to take a snapshot of a server that is basically creating a type of backup at the time - although it should not be used as a backup solution that needs to be kept for a length of time. The function of this works in a scenario when you need to upgrade software of an application, or on the operating system of a virtual machine. You can create a snapshot before commencing with the upgrade and once completed can do the upgrade. If it was unsuccessful and 
causes problems, you can revert the snapshot back to how the server was before, without the upgrades.

- VADP backups: This is a backup solution that uses snapshot technology and backs up the entire virtual machine as it is. When a virtual machine becomes problematic and needs to be restored you can restore it from the backup solution. This solution allows for lengthy periods of retaining data for protection. When snapshots are created and virtual machine is backed up, the snapshots are deleted.

- Storage Pool: A storage pool consist of an amount of storage assigned to a pool which is presented to the hypervisors.

- Capital Expenditure: Money spent on acquiring or upgrading fixed assets (purchasing physical hardware).

- Operational Expenditure: Money spend on ongoing/day-to-day basis in order to run a system (Paying monthly for maintenance support on old servers).

- Maintenance Support: Offered from vendors when troubleshooting of hardware is required, replacement of hardware components and server firmware upgrades.

Source: Developed by case writer 


\section{Exhibit 3: Cloud Computing}
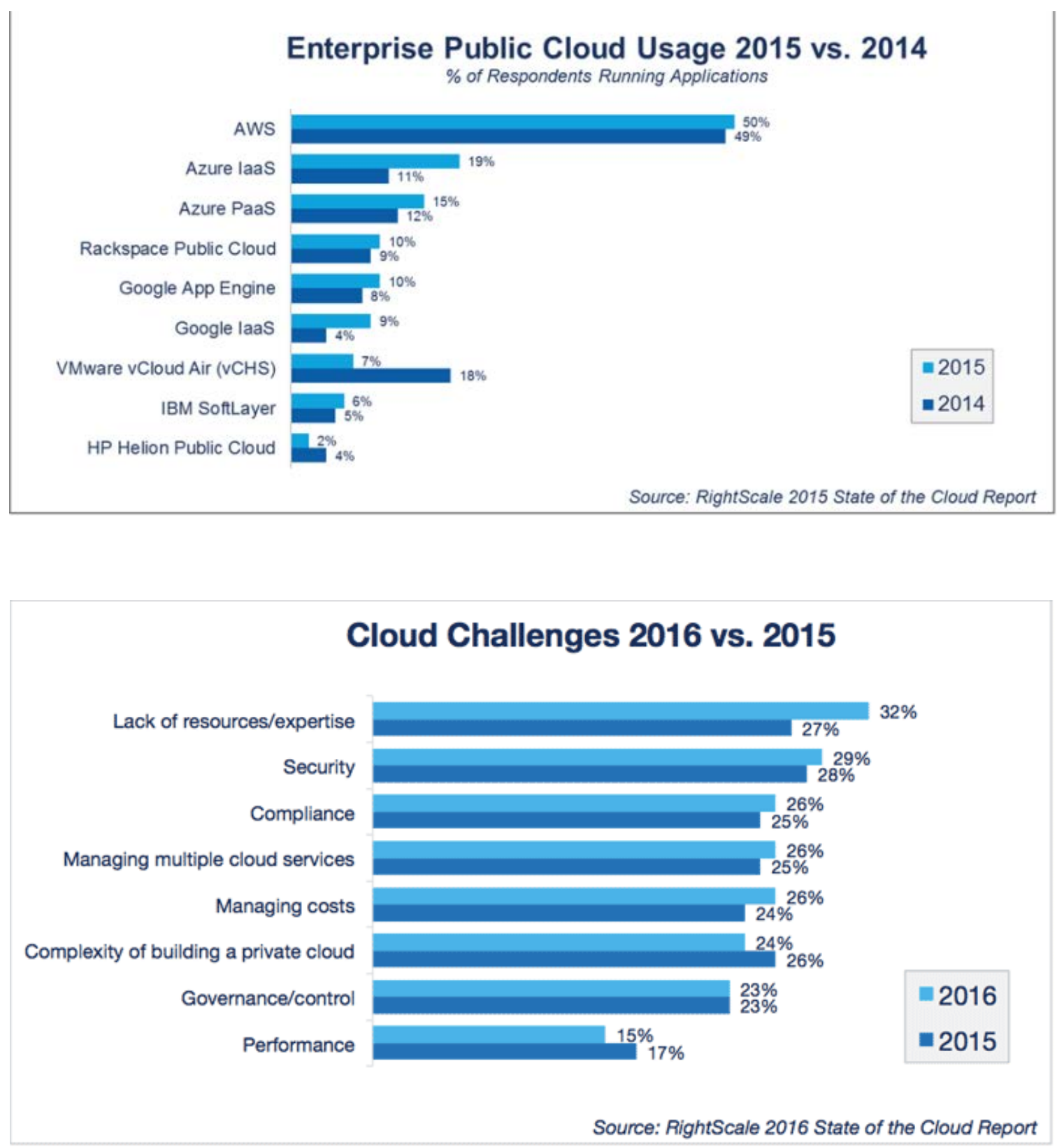


\section{Few Companies are Optimizing Cloud Costs}

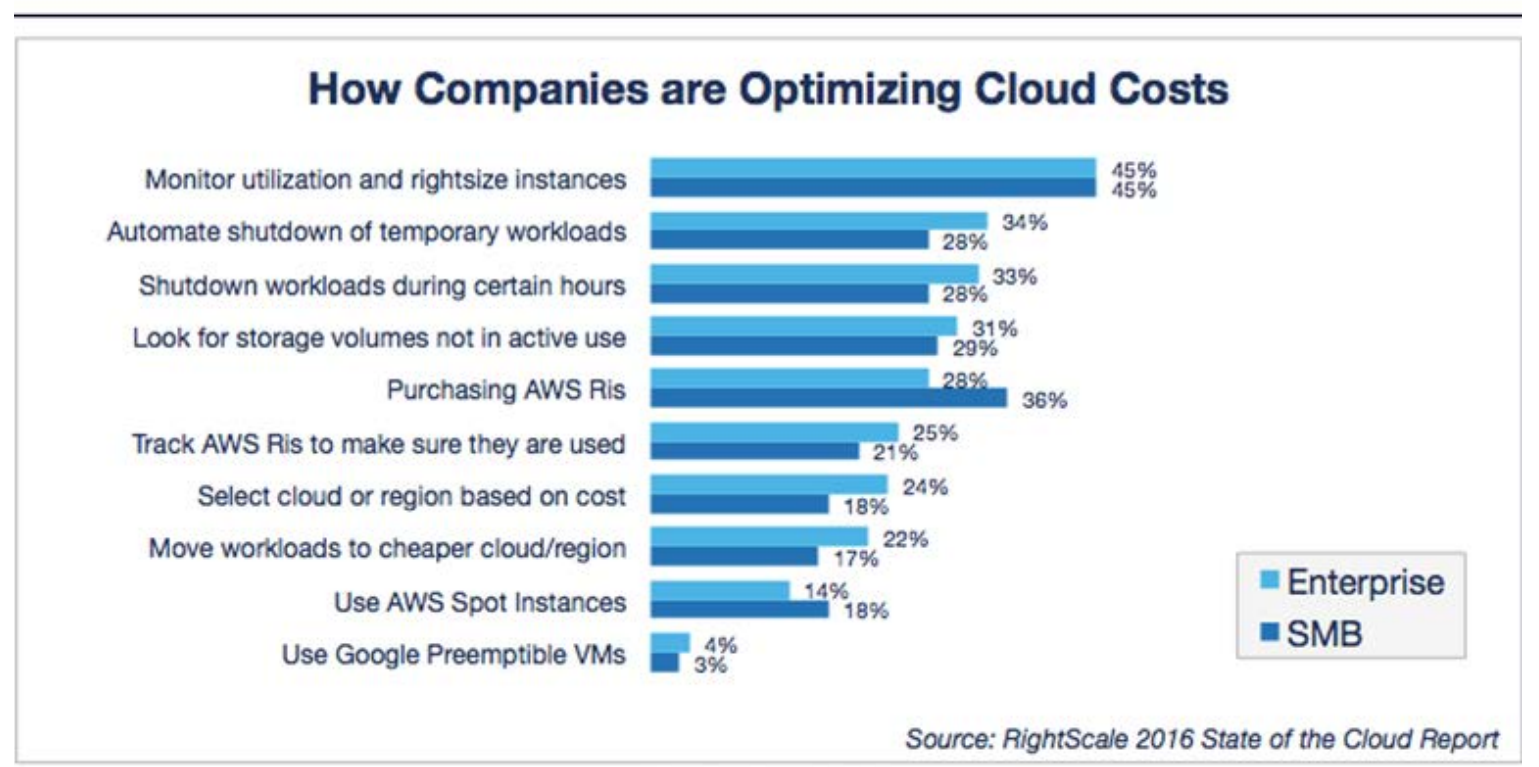

\section{RiتHT 5cale}

Source: Zdnet Website (http://www.zdnet.com/article/cloud-computing-goes-hybrid-as-the-norm-awsVMware-azure-duke-it-out/)

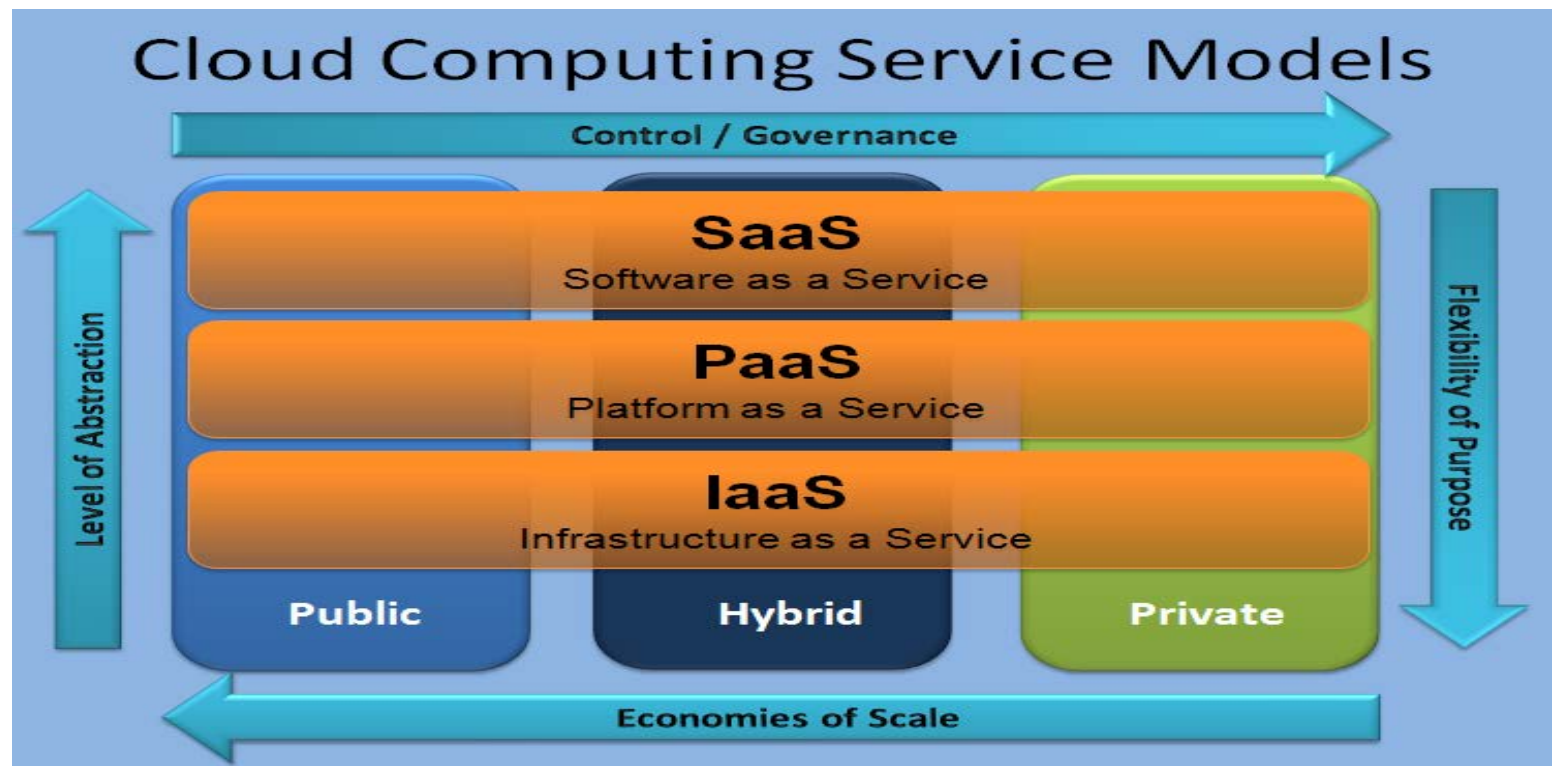




\section{Cloud Security Risk Areas}

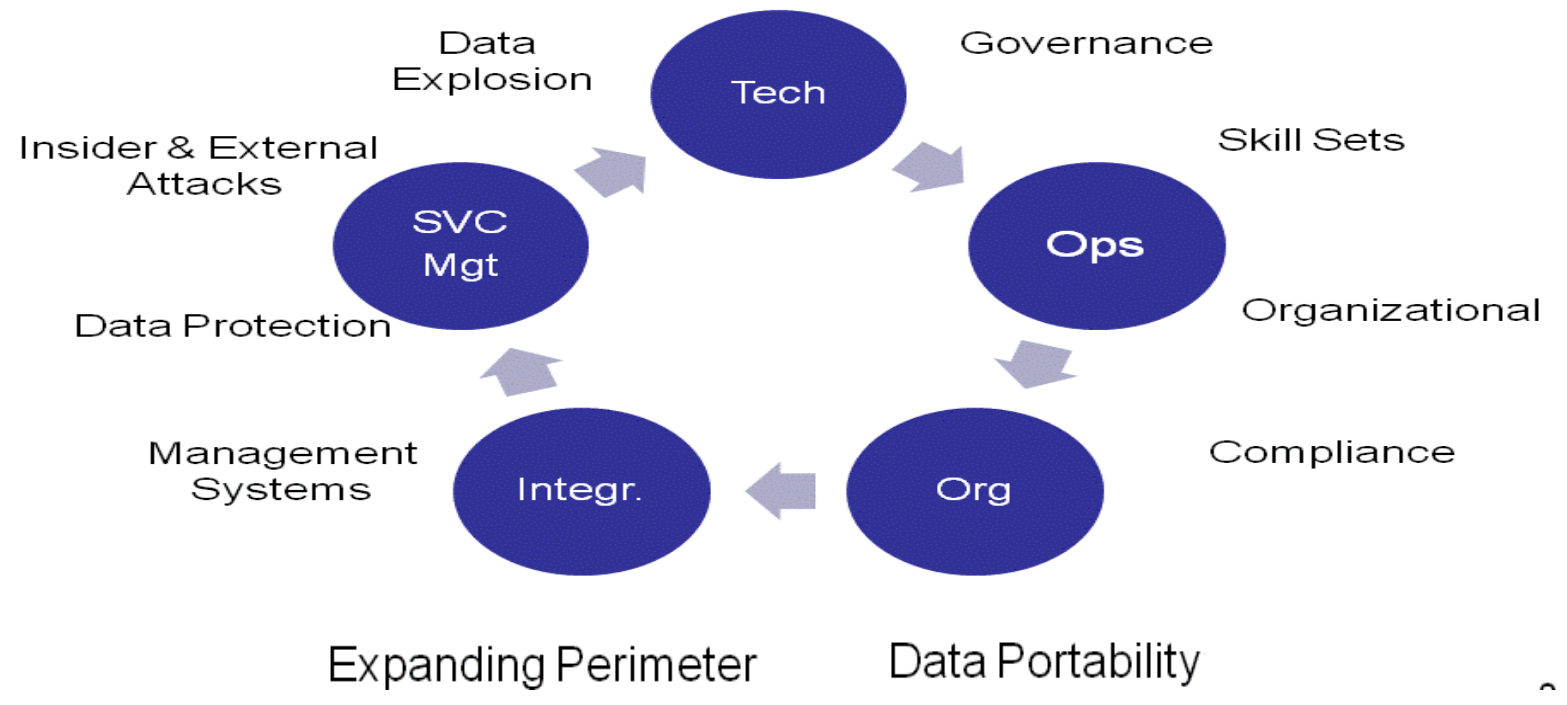

Source: 247newsday Website (http://247newsday.com/things-you-need-to-know-about-cloud-computingpart-3/) 
Exhibit 4: Why Perform Virtualization

\begin{tabular}{|l|l|}
\hline Support of moving to cloud & $\begin{array}{l}\text { Virtualizing and abstracting away the underlying } \\
\text { hardware prepares an organization for migration } \\
\text { from a virtualized Datacentre to a cloud Datacentre }\end{array}$ \\
\hline $\begin{array}{l}\text { Extending the life of legacy } \\
\text { applications }\end{array}$ & $\begin{array}{l}\text { Legacy applications that do not receive updates and } \\
\text { do not run on modern operating systems can have } \\
\text { its lifespan encapsulated and extended by } \\
\text { virtualization. }\end{array}$ \\
\hline Isolation of applications and processes & $\begin{array}{l}\text { In the physical world, data centers move to a one } \\
\text { app/one server model in order to isolate } \\
\text { applications. This causes physical server sprawl } \\
\text { and increased costs.Virtualization provides } \\
\text { application isolation and removes application } \\
\text { compatibility issues by consolidating many of these } \\
\text { virtual machines across far fewer physical servers. }\end{array}$ \\
\hline Energy saving and going green & $\begin{array}{l}\text { Migration of physical server to virtual machines } \\
\text { can have the effect of using fewer physical servers } \\
\text { and saving on energy. }\end{array}$ \\
\hline
\end{tabular}




\section{Virtualization Defined}

For those more visually inclined...

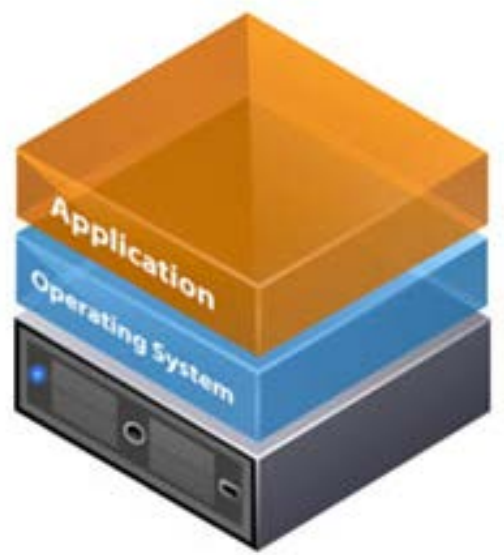

Traditional Architecture

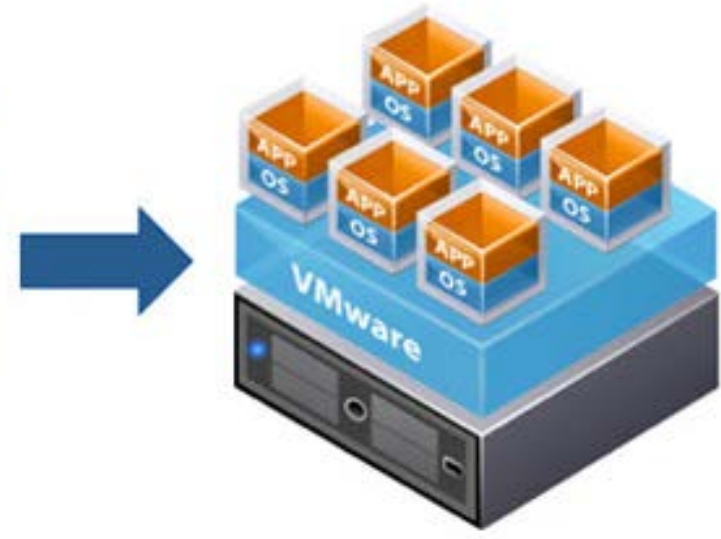

Virtual Architecture

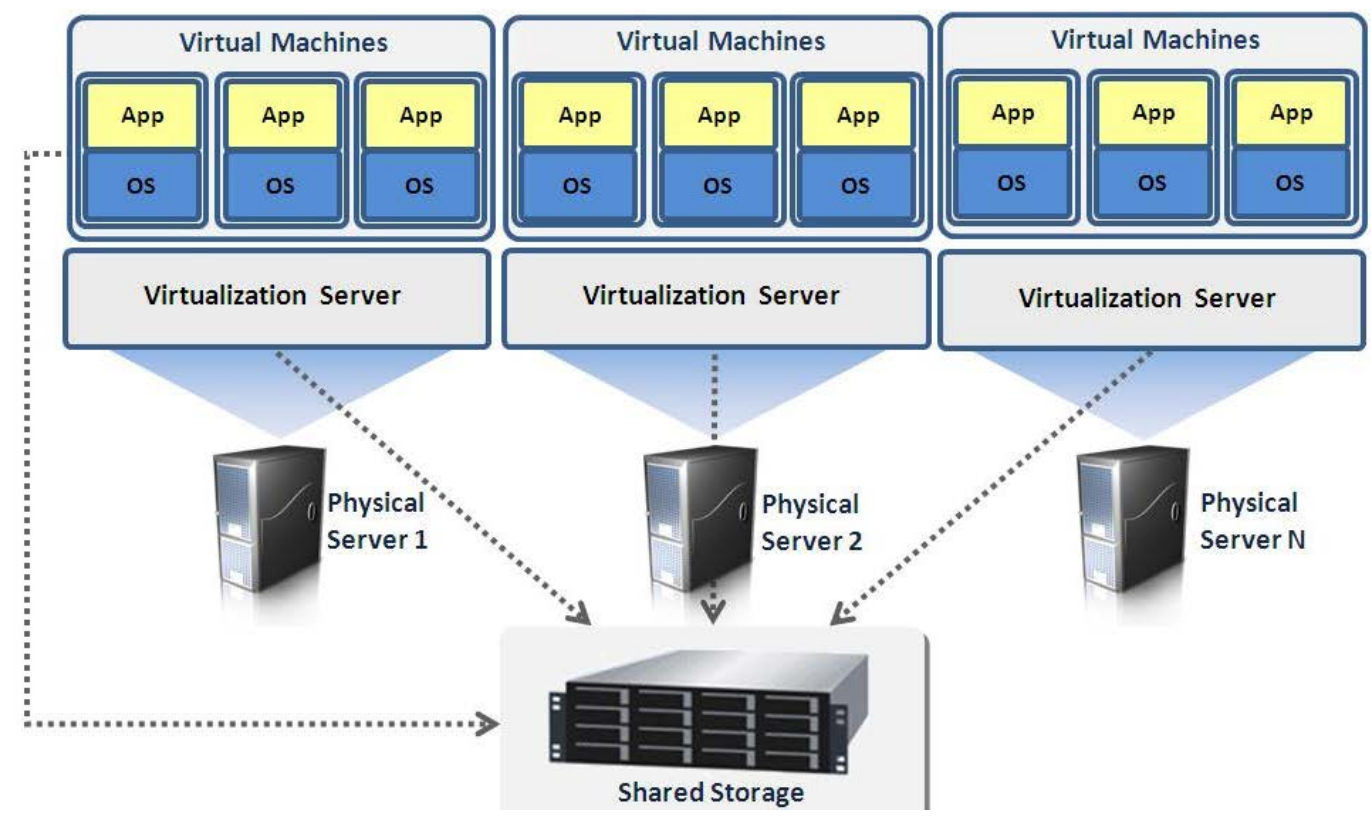

Source: Cryptumlimited Website (http://cryptumlimited.com/services/service specific/virtualization) 
Exhibit 5: Benefits of Virtualization

\begin{tabular}{|c|c|}
\hline $\begin{array}{l}\text { Reducing capital and operational } \\
\text { costs }\end{array}$ & $\begin{array}{l}\text { Legacy servers can be migrated to virtual } \\
\text { machines, meaning there is no need to purchase } \\
\text { new physical servers, as this can save on capital } \\
\text { costs. Also, operational maintenance costs are } \\
\text { saved as the need to maintain the legacy server } \\
\text { disappears. You can migrate legacy physical } \\
\text { server over fewer physical server hypervisors. }\end{array}$ \\
\hline Minimizing downtime & $\begin{array}{l}\text { Downtime is minimized, with the option of high } \\
\text { availability, with hypervisors configured into a } \\
\text { clustered environment. When a hypervisor fails, } \\
\text { the virtual machines will go and restart on other } \\
\text { available hypervisors. The time a virtual machine } \\
\text { takes to start is about } 5 \text { minutes, as Dumas } \\
\text { experienced in his own environment. The } \\
\text { requirement for this is that your hypervisors must } \\
\text { be clustered, must have a shared network switch } \\
\text { and shared storage between them. }\end{array}$ \\
\hline $\begin{array}{l}\text { Increasing IT productivity, efficiency, } \\
\text { agility and responsiveness }\end{array}$ & $\begin{array}{l}\text { Virtual machines can be built on demand, CPU, } \\
\text { memory and storage can be added to the virtual } \\
\text { machine instantly, with downtime or without, } \\
\text { workloads of virtual machines can be load } \\
\text { balanced automatically when a hypervisor is } \\
\text { running at peak performance, and hypervisors } \\
\text { can be added to the clustered environment } \\
\text { without any hassles to increase cluster resources. }\end{array}$ \\
\hline $\begin{array}{l}\text { Enabling business continuity and } \\
\text { disaster recovery }\end{array}$ & $\begin{array}{l}\text { Certain product solutions can be integrated, } \\
\text { which allows that if one site fails, the virtual } \\
\text { machines can start up on another site. Usually } \\
\text { this is called replication of storage or application. }\end{array}$ \\
\hline Simplifying datacenter management & $\begin{array}{l}\text { Your whole virtual environment can be } \\
\text { controlled from one centralized application. } \\
\text { Servers that sit in other regions and countries can } \\
\text { be managed from one application. }\end{array}$ \\
\hline $\begin{array}{l}\text { Building a software defined } \\
\text { datacentre }\end{array}$ & $\begin{array}{l}\text { Reduction of physical hardware that is } \\
\text { virtualized and delivers the exact same services } \\
\text { as that of physical servers. Automation is also } \\
\text { available by being able to demand a server, } \\
\text { storage or compute resources within minutes. }\end{array}$ \\
\hline
\end{tabular}


Source: VMware Website (http://www.VMware.com/solutions/virtualization.html)

\section{Exhibit 6: Minimizing Downtime with High Availability}

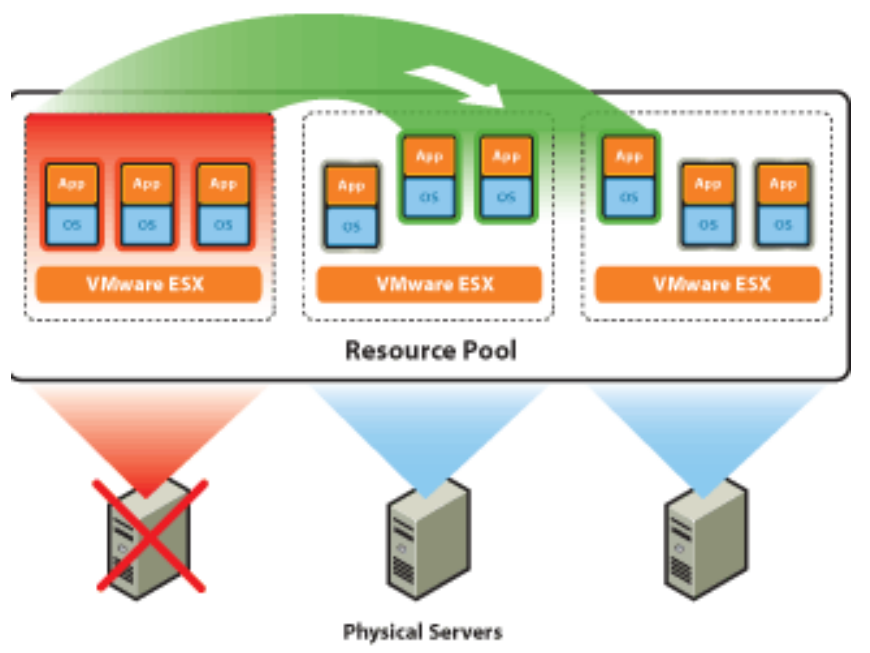

Source: VMware Website (http://www.vmvault.com.au/index.php/hosting/VMware-vsphere-benefits)

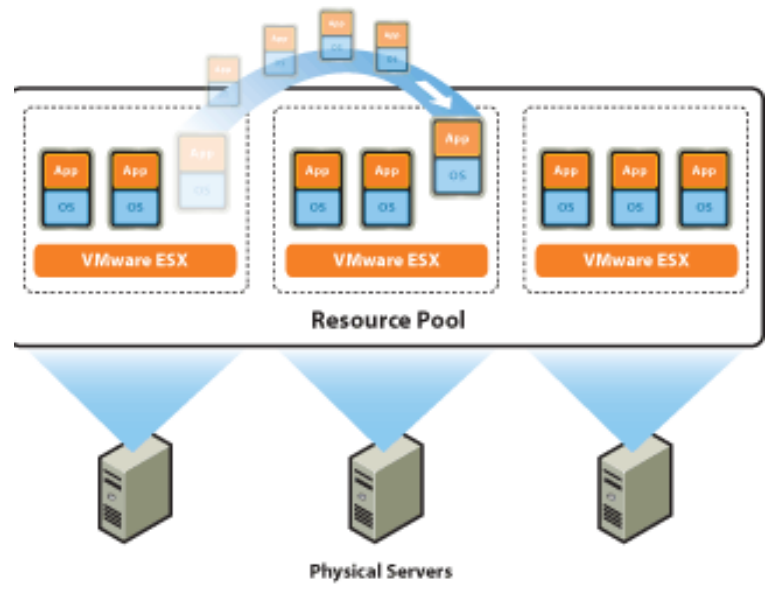

Source: Hostway Website (https://www.hostway.de/VMware/VMware-suite/drs/) 


\section{Exhibit 7: Consumer Barriers to Mobile Internet Adoption in Africa}

\section{Breakdown of mobile internet, voice and text, and non-mobile} subscribers at the end of 2015

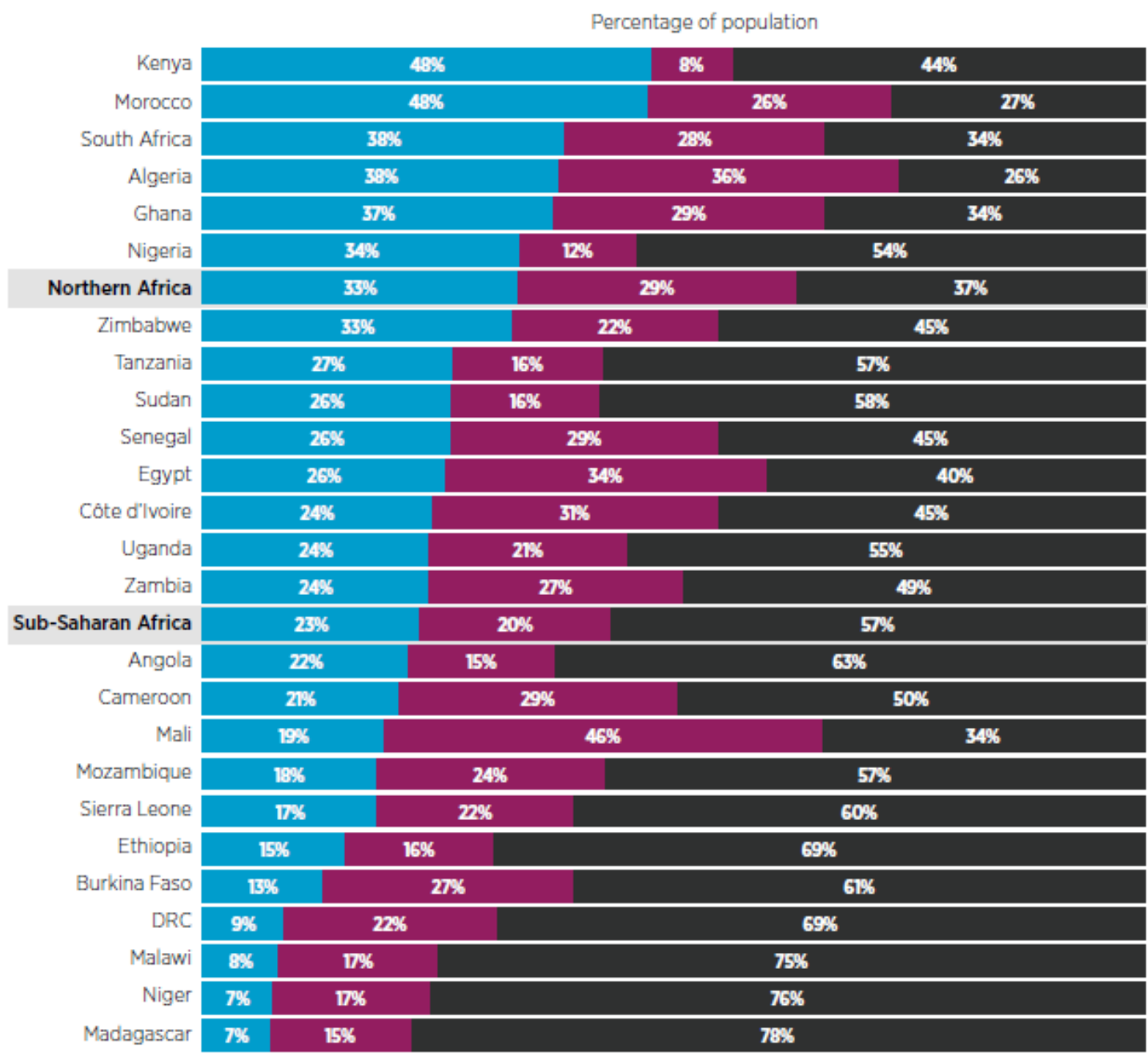

Mobile internet Voice and text only Non-mobile

Source: GSMA Intelligence Website (https://www.gsmaintelligence.com/) 


\section{Exhibit 8: Virtualization Matrix from Gartner}

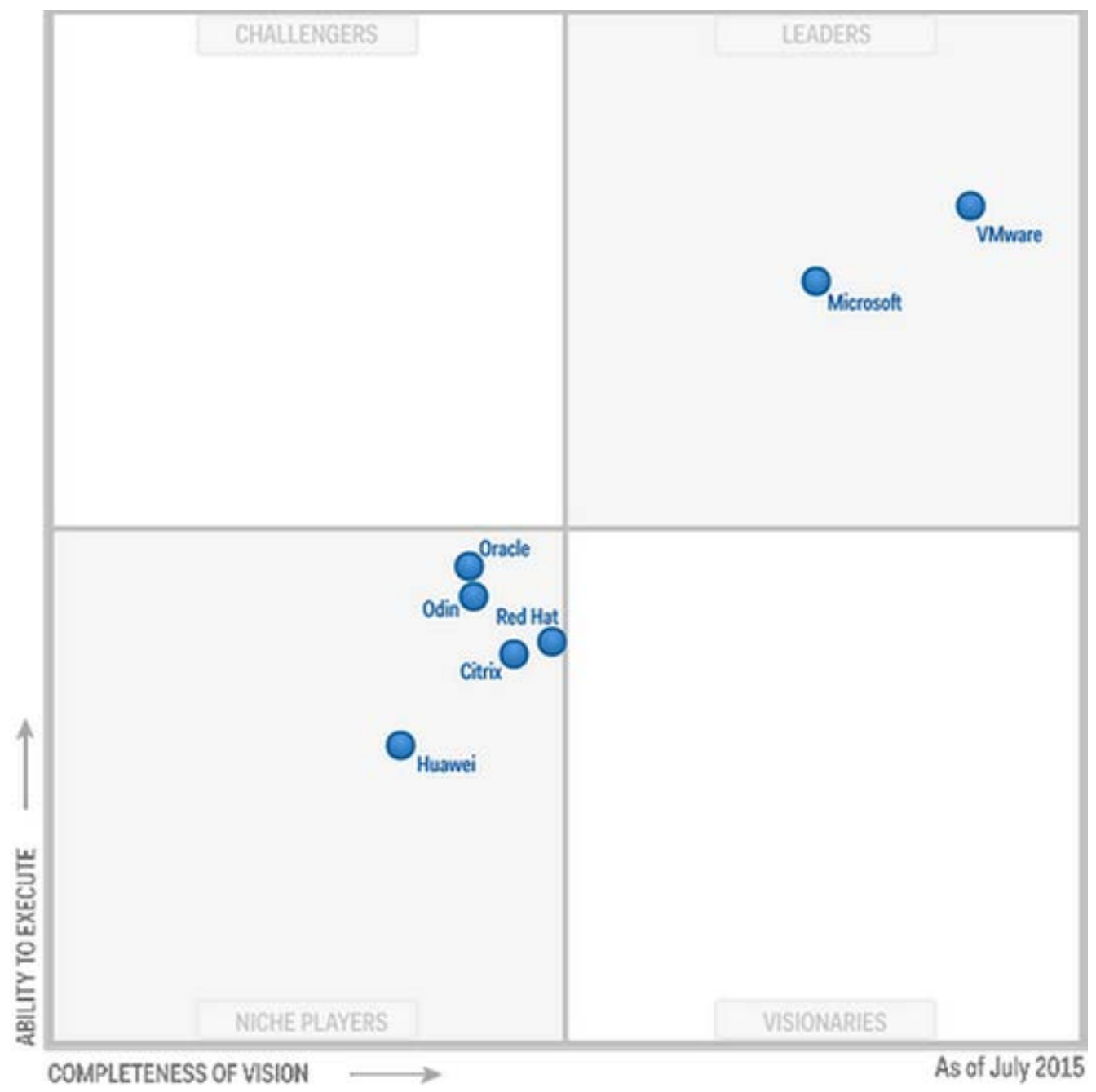

Source: Zdnet Website (http://www.zdnet.com/article/gartners-magic-quadrant-for-x86-servervirtualization-infrastructure-is-a-head-scratcher/) 
Exhibit 9: Comparison of Virtualization Products (WhatMatrix)

\begin{tabular}{|c|c|c|c|}
\hline & VSphere & Hyper - V & XenServer \\
\hline Vendor & VMware & Microsoft & Citrix \\
\hline Costs & $\begin{array}{l}\text { vSphere is licensed per } \\
\text { physical CPU (socket, } \\
\text { not core), without } \\
\text { restrictions on the } \\
\text { amount of physical } \\
\text { cores or virtual RAM } \\
\text { configured }\end{array}$ & $\begin{array}{l}\text { A single Standard } \\
\text { license covers up to } 2 \\
\text { physical CPUs. Support } \\
\text { for Hyper-V is part of } \\
\text { the support for } \\
\text { Windows operating } \\
\text { system (not included in } \\
\text { OS license). }\end{array}$ & $\begin{array}{l}\text { Open Source (free) or } \\
\text { two commercial } \\
\text { editions. For } \\
\text { commercial editions } \\
\text { (Standard or Enterprise) } \\
\text { XenServer is licensed } \\
\text { on a per-CPU socket } \\
\text { basis. For a pool to be } \\
\text { considered licensed, all } \\
\text { XenServer hosts in the } \\
\text { pool must be licensed. } \\
\text { XenServer only counts } \\
\text { populated CPU sockets. }\end{array}$ \\
\hline $\begin{array}{l}\text { Hypervisor Max } \\
\text { CPU }\end{array}$ & 480 Physical & 320 logical CPU & 160 logical \\
\hline $\begin{array}{l}\text { Hypervisor Max } \\
\text { Memory }\end{array}$ & $12 \mathrm{~TB}$ & 4TB & $1 \mathrm{~TB}$ \\
\hline $\begin{array}{l}\text { Max Core per } \\
\text { CPU }\end{array}$ & Unlimited & Unlimited & Unlimited \\
\hline $\begin{array}{l}\text { Max Virtual CPU } \\
\text { per VM }\end{array}$ & 128 vCPU & $\begin{array}{l}64 \text { vCPU (Windows),64 } \\
\text { vCPU (Linux) }\end{array}$ & $\begin{array}{l}16 \text { vCPU (Windows),32 } \\
\text { vCPU (Linux) }\end{array}$ \\
\hline $\begin{array}{l}\text { Max Virtual } \\
\text { Memory per VM }\end{array}$ & $4 \mathrm{~TB}$ & $1 \mathrm{~TB}$ & 192GB \\
\hline $\begin{array}{l}\text { Max Virtual Disk } \\
\text { Size }\end{array}$ & 62TB VMDK & $\begin{array}{l}\text { 64TB (vhdx), 2TB } \\
\text { (vhd), 256TB+ (raw) }\end{array}$ & $2 \mathrm{~TB}$ \\
\hline Cloud & vCloud Air & $\begin{array}{l}\text { Cloud OS: System } \\
\text { Center, Hyper-V, Azure }\end{array}$ & CloudPlatform \\
\hline
\end{tabular}


THOMAS \& VAN BELLE

\begin{tabular}{|c|c|c|c|}
\hline Cloud API & vCloud API & $\begin{array}{l}\text { Service Provider } \\
\text { Foundation API, Azure } \\
\text { Service Management } \\
\text { API }\end{array}$ & $\begin{array}{l}\text { CloudStack APIs, } \\
\text { support for AWS API }\end{array}$ \\
\hline $\begin{array}{l}\text { VM per } \\
\text { hypervisor }\end{array}$ & $1024 \mathrm{VMs}$ & $\begin{array}{l}1024 \text { vims/host, } 2048 \\
\text { vCPUs/host }\end{array}$ & 1000 VMs per host \\
\hline $\begin{array}{l}\text { Replication/Site } \\
\text { Failover }\end{array}$ & $\begin{array}{l}\text { Limited (native): } \\
\text { vSphere Replication } \\
\text { Yes (with Vendor Add- } \\
\text { On: SRM) }\end{array}$ & $\begin{array}{l}\text { Hyper-V Replica } \\
\text { (extended replication } \\
\text { and replication } \\
\text { frequency - NEW) }\end{array}$ & $\begin{array}{l}\text { Integrated Disaster } \\
\text { Recovery (no storage } \\
\text { array control) }\end{array}$ \\
\hline Cluster Size & $\begin{array}{l}\text { max } 64 \text { nodes / } 8000 \mathrm{vm} \\
\text { per cluster }\end{array}$ & 64 nodes / 8000 vims & 16 hosts / resource pool \\
\hline Patching & $\begin{array}{l}\text { Limited (Update } \\
\text { Manager) }\end{array}$ & $\begin{array}{l}\text { Yes (WSUS, SCCM, } \\
\text { VMST) }\end{array}$ & No \\
\hline
\end{tabular}

Source: Whatmatrix Website (https://www.whatmatrix.com/comparison/Virtualization\#) 


\section{Exhibit 10: Difference Between Virtual Machine and Containers}

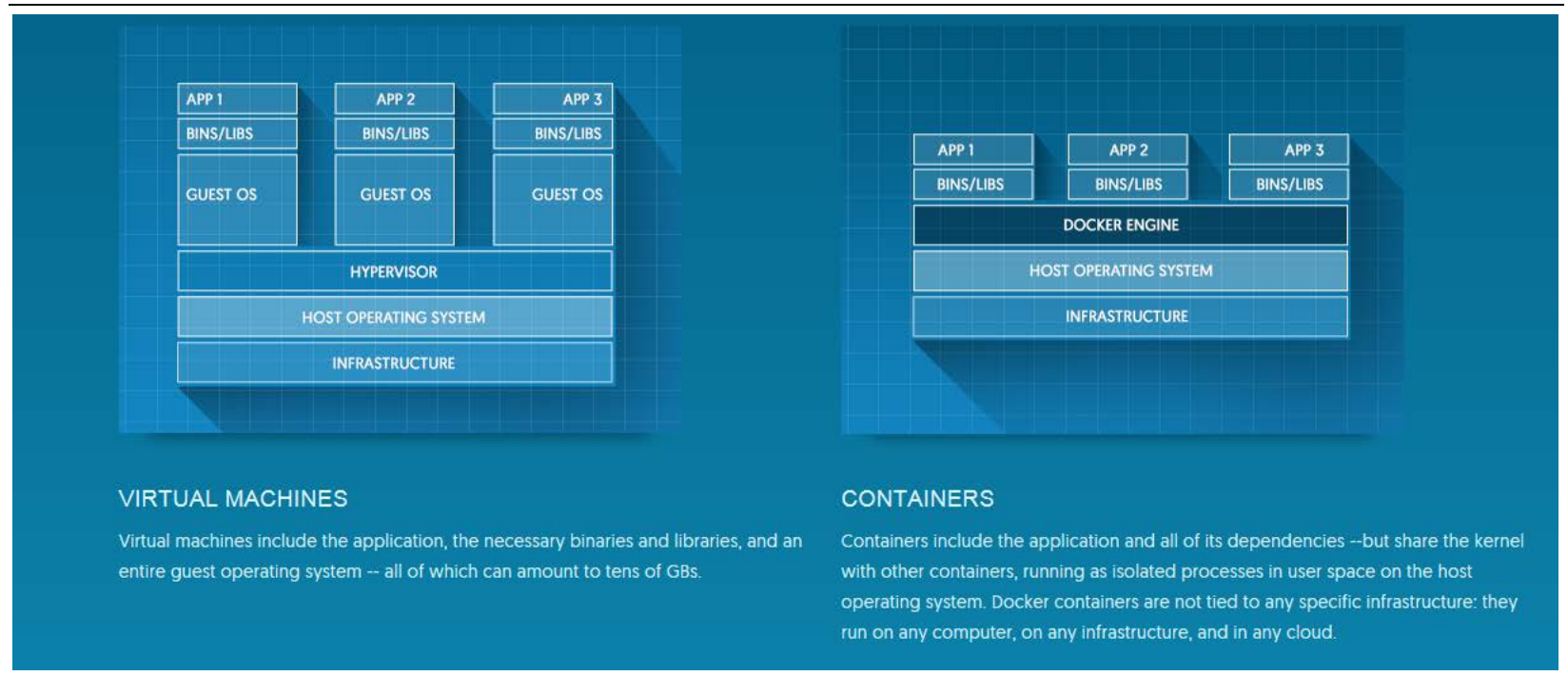

Source: Docker Website (https://www.docker.com/)

\begin{tabular}{|c|c|}
\hline Containers & Virtual machines \\
\hline created in a second & created in 1-2 minutes \\
\hline requires less memory space & allocate the given amount of memory \\
\hline very fast launch time & harder logical boundaries \\
\hline higher level isolation & lower level isolation \\
\hline protected from colliding & not protected from colliding \\
\hline highly portable & highly portable \\
\hline share operating system libraries & don't share libraries with the host \\
machine
\end{tabular}

Source: SuperAdmins Website (https://superadmins.com/container-the-game-changer-2/) 


\title{
Exhibit 11: Blades, Converge Systems and Superdomes
}

\section{Blades}

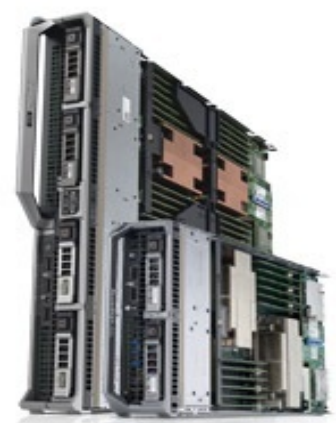

\begin{abstract}
Customers seeking a simple, fast, cool and dense modular-server solution with uncompromised performance.
\end{abstract}

New PowerEdge M630 Blade Server

Source: Dell Website (http://www.dell.com/us/business/p/poweredge-blade-servers\#!tabId=6A38ED6A) 


\section{Converge Systems}

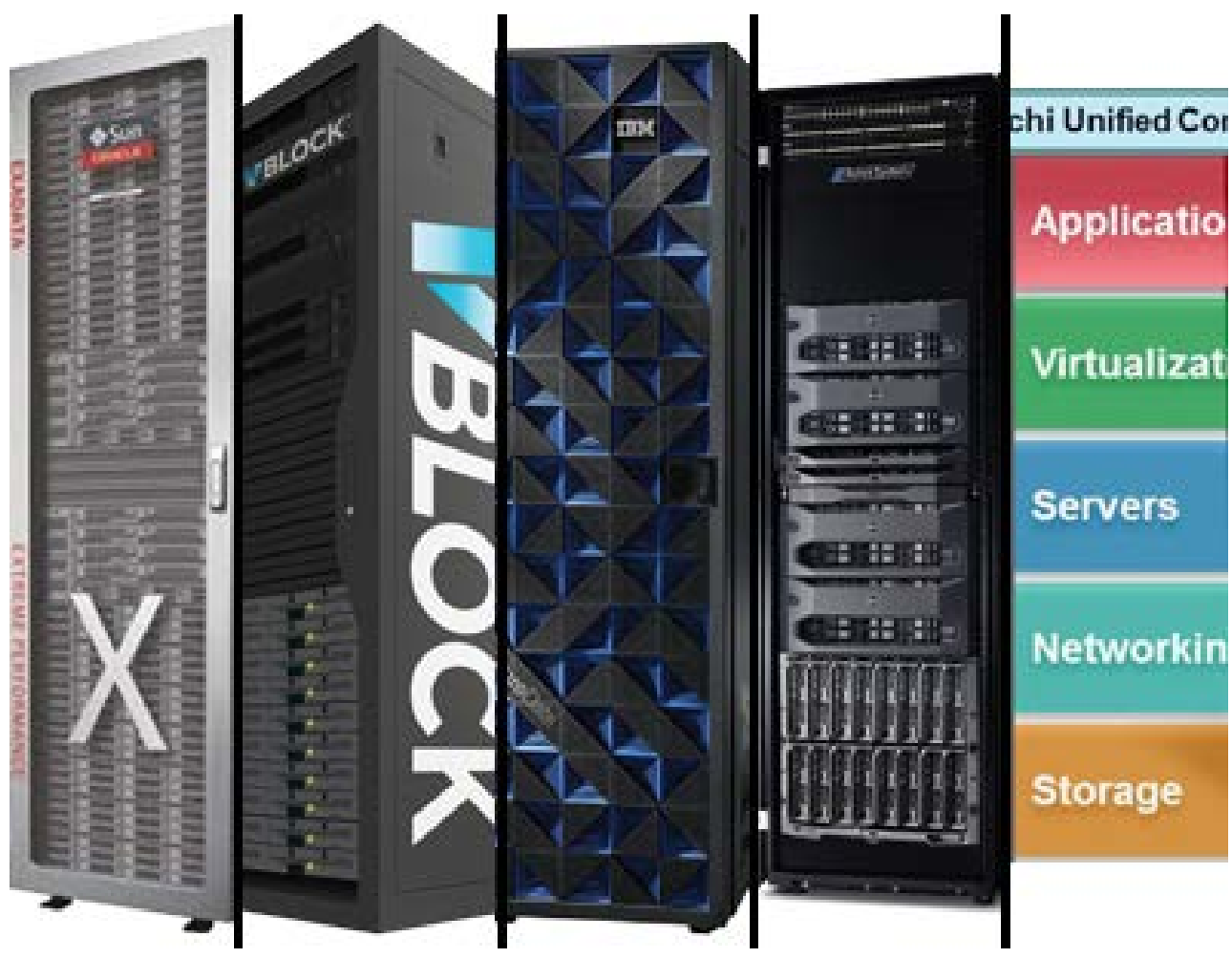

Source: Datacenter Dynamics Website

(http://archive.datacenterdynamics.com/focus/archive/2012/11/converged-systems-market-warms) 


\section{Superdomes}

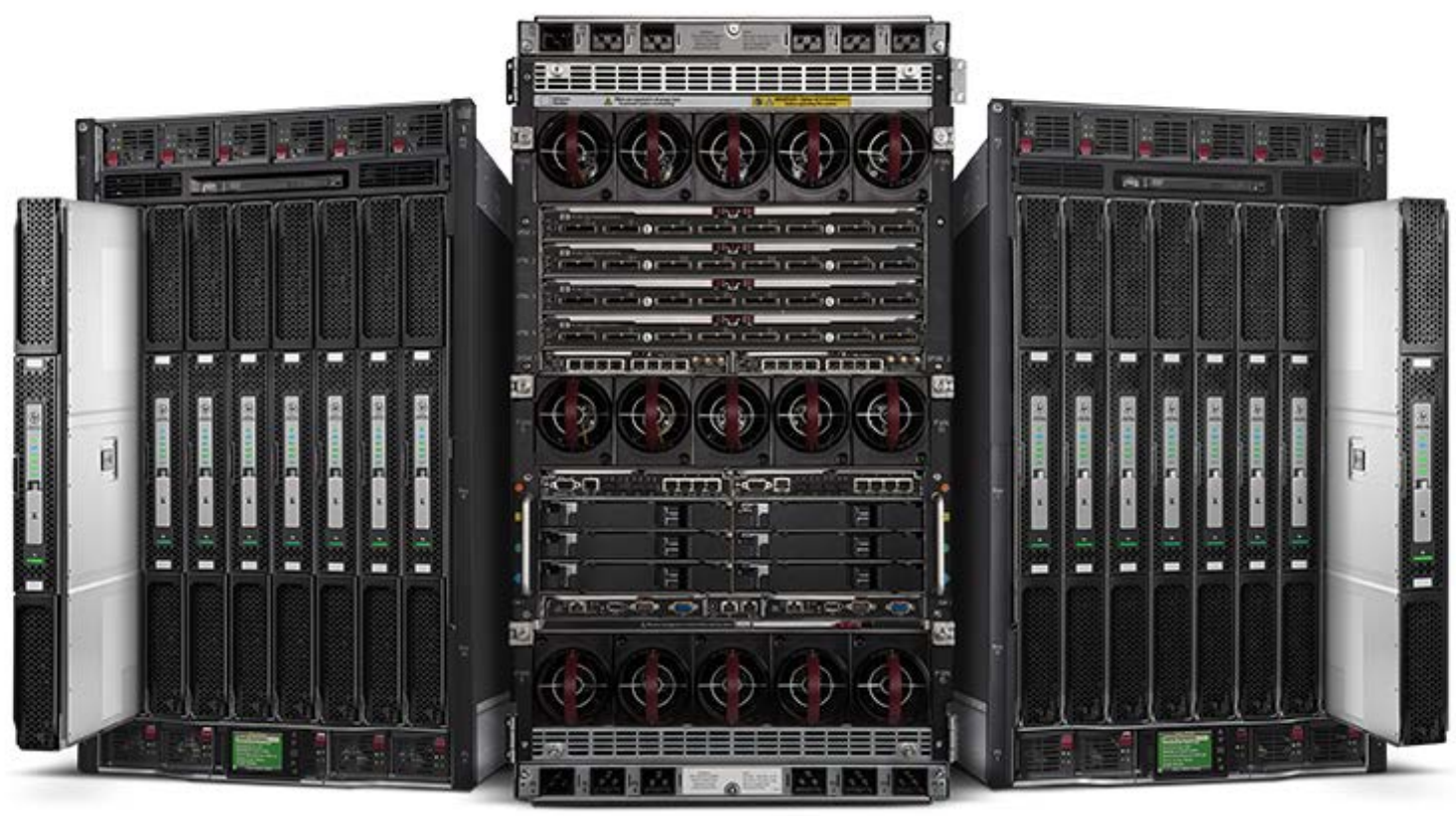

Source: HPE Website (https://www.hpe.com/us/en/servers/superdome.html)

\begin{tabular}{|c|c|c|}
\hline $\begin{array}{l}\text { Individual x86 } \\
\text { Blades }\end{array}$ & $\begin{array}{l}\text { Converge } \\
\text { Systems with } \\
\text { x86 Blades }\end{array}$ & Superdomes \\
\hline $\begin{array}{l}\text { A blade is literally a self- } \\
\text { contained server, which } \\
\text { collectively fits into an } \\
\text { enclosure with other blades. } \\
\text { Sometimes known as a } \\
\text { chassis, this enclosure } \\
\text { provides the power, cooling, } \\
\text { connectivity, and } \\
\text { management to each blade } \\
\text { server. The blade servers } \\
\text { themselves contain only the } \\
\text { core processing elements, } \\
\text { making them hot-swappable. }\end{array}$ & $\begin{array}{l}\text { Integrates compute, storage, } \\
\text { and networking resources. } \\
\text { Moving to a converged } \\
\text { infrastructure ties } \\
\text { virtualization, automation, } \\
\text { and unified infrastructure } \\
\text { management software } \\
\text { together into pre-built, tested, } \\
\text { and workload-optimized } \\
\text { systems. These systems are } \\
\text { software-defined for easy } \\
\text { integration into existing } \\
\text { infrastructure and quick } \\
\text { transition to hybrid cloud } \\
\text { delivery models. }\end{array}$ & $\begin{array}{l}\text { HPE Integrity Superdome X is } \\
\text { a mission-critical x86 server } \\
\text { solution that combines the } \\
\text { proven HPE Integrity } \\
\text { Superdome } 2 \text { line availability } \\
\text { and reliability, with industry- } \\
\text { standard x86 processors and } \\
\text { support for popular Linux®, } \\
\text { Microsoft Windows and } \\
\text { VMware environments. The } \\
\text { HPE BladeSystem Superdome } \\
\text { Enclosure is the building block } \\
\text { for Superdome X, featuring } \\
\text { configurations of one to eight } \\
\text { scalable x86 blades with } \\
\text { support for electrical isolation } \\
\text { via hard partitions (HPE nPars) } \\
\text { of one, two, three, four, six or }\end{array}$ \\
\hline
\end{tabular}




\begin{tabular}{|l|l|l|}
\hline & & $\begin{array}{l}\text { eight blades. Multiple nPars of } \\
\text { different sizes are supported } \\
\text { within a single enclosure, } \\
\text { assuring your most critical } \\
\text { workloads are protected from } \\
\text { other application failures. } \\
\text { Breakthrough innovations such } \\
\text { as a fault-tolerant Crossbar } \\
\text { Fabric and Error Analysis } \\
\text { Engine coupled with the hard } \\
\text { partitioning capabilities, sets up } \\
\text { Superdome X as the standard } \\
\text { for mission-critical x86 } \\
\text { computing. }\end{array}$ \\
\hline $\begin{array}{l}\text { The need for more network } \\
\text { ports and network cables for } \\
\text { each blade server in an } \\
\text { enclosure. }\end{array}$ & $\begin{array}{l}\text { Less Network cables needed } \\
\text { as blades are interconnected. } \\
\text { Has a Virtual connect module } \\
\text { that allows connectivity to } \\
\text { network switches. }\end{array}$ & $\begin{array}{l}\text { Comes with a pass through } \\
\text { model to connect to the } \\
\text { network and requires less } \\
\text { network cables. }\end{array}$ \\
\hline $\begin{array}{l}\text { Needs to connect to a Storage } \\
\text { Area Network or purchased } \\
\text { with local disks (non- } \\
\text { shareable). }\end{array}$ & $\begin{array}{l}\text { Converge enclosure comes } \\
\text { with a Storage Area network } \\
\text { that is built in and shared } \\
\text { across all blade servers in the } \\
\text { enclosure. }\end{array}$ & $\begin{array}{l}\text { Needs to connect to a Storage } \\
\text { Area Network. }\end{array}$ \\
\hline
\end{tabular}

Source: HPE Website (https://www.hpe.com/us/en/integrated-systems/converged.html) 


\section{Use of x86 Blade Servers}

\begin{tabular}{|l|l|}
\hline Virtualization & $\begin{array}{l}\text { Supports all virtualization product suites: Hyper-V, } \\
\text { Citrix Xen, VMware etc. Also support for virtual } \\
\text { desktops between normal and power users. }\end{array}$ \\
\hline Cloud & $\begin{array}{l}\text { Can support private and public cloud, through } \\
\text { specialized products. }\end{array}$ \\
\hline Big Data Applications & $\begin{array}{l}\text { Support for databases and transactional processing } \\
\text { that demands power from compute resources. } \\
\text { Application examples are SAP, Microsoft SQL } \\
\text { Oracle etc. }\end{array}$ \\
\hline Operating systems & Supports most operating systems that are available. \\
\hline Streaming & Audio and video streaming is supported. \\
\hline
\end{tabular}

Source: HPE Website (https://www.hpe.com/us/en/integrated-systems/converged.html) 


\section{Exhibit 12: Retaining vs Purchasing of Server Hardware}

\begin{tabular}{|c|c|}
\hline Retaining the existing legacy hardware & Replacing the existing legacy hardware \\
\hline $\begin{array}{l}\text { Keeping the server environment requires renewal of } \\
\text { support and maintenance contracts. Retaining would } \\
\text { decrease the costs of capital expenditure, but would } \\
\text { increase the cost of operational expenditure. This } \\
\text { also allows no downtime as virtual machines would } \\
\text { need to be migrated to new or existing hardware, } \\
\text { which would require downtime. Server Vendor } \\
\text { firmware would still be upgradable to a point, } \\
\text { although to be able to stay in maintenance the } \\
\text { virtualization software would not be able to be } \\
\text { upgraded due to Vendor baselines. As the servers } \\
\text { were older than } 5 \text { years, they would not have the } \\
\text { same benefits of the new virtualization software, but } \\
\text { would be able to run and receive support from } \\
\text { vendors. } \\
\text { There would be a point in time when server hardware } \\
\text { would need to be replaced due to the hardware not } \\
\text { being able to keep up with performance demands, } \\
\text { support on servers becoming unavailable, so old } \\
\text { firmware / hardware upgrades would become } \\
\text { impossible and maintaining older server components } \\
\text { may cost more over a longer period. Service and } \\
\text { maintenance for older servers requires more work } \\
\text { but costs less than the traditional decommission and } \\
\text { replace standard. } \\
\text { Virtualization clustering is an option that could } \\
\text { increase performance for retaining older servers } \\
\text { which allows reduced downtime of server failures. If } \\
\text { your older servers can still meet the demand, then } \\
\text { keeping older server hardware will be more } \\
\text { beneficial than spending on newer servers, as new } \\
\text { hardware is costly. }\end{array}$ & $\begin{array}{l}\text { Replacing the older hardware with new server } \\
\text { hardware would create opportunity that would } \\
\text { give company technology higher performance } \\
\text { for future growth and savings on operational } \\
\text { costs for server maintenance, as it would be } \\
\text { included. The reason for replacing older } \\
\text { hardware would be that systems become too } \\
\text { costly to maintain or are not efficient enough for } \\
\text { company growth. With newer hardware, there is } \\
\text { the opportunity to deploy more virtual machines, } \\
\text { reduce Datacenter space, energy and power } \\
\text { requirements by purchasing higher server } \\
\text { compute resources. This prevents having to } \\
\text { purchase the same amount of servers that are } \\
\text { needed to replace decommissioned servers. This } \\
\text { provides efficient resources to applications that } \\
\text { need more resource performance from } \\
\text { technology. } \\
\text { Technology is always advancing and becoming } \\
\text { more optimal in performance, so implementing } \\
\text { the latest technology can save a considerable } \\
\text { amount of money in the future. Keeping up to } \\
\text { date with trends intended for new technology } \\
\text { and evaluating it objectively against the financial } \\
\text { impact on a company, enables you to align } \\
\text { technology with company strategy and } \\
\text { competitiveness. New technology helps to } \\
\text { ensure more with less money - replacing older } \\
\text { hardware with new hardware reduces the } \\
\text { additional complexity and costs (Cassidy, 2009). }\end{array}$ \\
\hline
\end{tabular}

Source: Developed by Mark Dumas 